\title{
EL PRIMER APORTE DE LOS OBISPOS CHILENOS A LA CODIFICACIÓN DEL DERECHO CANÓNICO DE 1917: LOS POSTULATA EPISCOPORUM ACERCA DEL MATRIMONIO***
}

\begin{abstract}
La redacción del primer Código de Derecho Canónico que tuvo la Iglesia latina fue ordenado por el papa san Pío X, en 1904. La tarea codificadora, empero, no fue obra de un grupo cerrado de expertos, sino que tuvo en cuenta el parecer del episcopado, el que fue consultado en dos momentos diferentes; en ambos casos fueron requeridos los obispos chilenos. En este trabajo se estudia, a partir de la documentación guardada en el Archivo Secreto Vaticano, el aporte de los obispos chilenos en la primera consulta, realizada en 1904, en lo referido al matrimonio.
\end{abstract}

Palabras clave: codificación canónica, Código de Derecho Canónico de 1917, obispos chilenos, postulata episcoporum, matrimonio.

The drafting of the first Código de Derecho Canónico of the Latin Church was established by Pope Pío X in 1904. The codifying task, however, was not the result of a closed group of experts. It considered the opinion of bishops around the world who were consulted in two different moments. In both cases, Chilean bishops were requested to provide their opinions. This work, which is based on documents from the Vatican Secret Archives, studies the contribution of Chilean bishops to the marriage discussion in the first round of consultation of 1904.

Key words: Canonic Codification, Código de Derecho Canónico of 1917, Chilean bishops, postulata episcoporum marriage.

Fecha de recepción: marzo 2008

Fecha de aceptación: agosto 2008

\footnotetext{
* Pontificia Universidad Católica de Valparaíso, Facultad de Derecho. Correo electrónico: csalinas@ucv.cl.

** Este trabajo forma parte del proyecto de investigación Fondecyt 1070434 del que el autor es investigador responsable.
} 


\section{LA CODIFICACIÓN DEL DERECHO CANÓNICO***}

La tarea de elaborar un Codex Iuris Canonici que sustituyera al Corpus fue iniciada por el papa san Pío X (1903-1914) a poco de haber iniciado su pontificado, en los albores del siglo XX. Lo hizo mediante el motu proprio Arduum sane munus, del 19 de marzo de $1904^{1}$, mediante el cual creó una comisión pontificia encargada de asumir la codificación del derecho de la Iglesia ${ }^{2}$. La elaboración del Código, sin embargo, no fue una tarea de un grupo cerrado de iniciados, sino que, contando con el trabajo de un número importante de expertos bajo la dirección de Pedro Gasparri ${ }^{3}$, el mismo motu proprio dispuso la intervención de todo el episcopado latino ${ }^{4}$. De esta manera, una de las principales características del proceso de codificación del derecho canónico de 1917 consistió en la participación, promovida por la misma Santa Sede, del episcopado latino en la elaboración del Codex. Dicha participación, por cierto la primera requerida por la Iglesia al emprender la tarea de elaborar un cuerpo legislativo universal, se articuló en dos grandes momentos: el primero, al inicio de los trabajos de codificación, a través de los Postulata episcoporum; el segundo, en pleno procedo codificador, cuando se estaba llegando a la fase conclusiva de la misma, a través de las Animadversiones episcoporum. De ambos es el primero el que ahora nos interesa.

La primera de dichas consultas fue llevada a la práctica mediante la circular Pergratum mihi, de la Secretaría de Estado, enviada el 25 de marzo de 1904 a todos los metropolitanos 5 . En ella se disponía que los arzobispos, después de haber oído a sus sufragáneos y otros ordinarios con derecho a estar presentes en el concilio provincial, debían hacer llegar a la Santa Sede, dentro de los cuatro meses siguientes, en pocas palabras, las principales modificaciones y correcciones que debían hacerse al derecho canónico en vigor. En la misma circular se indicaba que era deseo formal del Papa ver a todo el episcopado concurrir y tomar parte activa en un asunto que interesaba en grado máximo al bien y utilidad de toda la Iglesia

*** Abreviaturas: AAS: Acta Apostolicae Sedis, Ciudad del Vaticano; ASS: Acta Sancta Sedis, Roma; ASV. CIC 17: Archivo Secreto Vaticano, Fondo Codificación del Derecho Canónico de 1917; BEAS: Boletín Eclesiástico del Arzobispado de Santiago, Santiago; BL: Boletín de Leyes, Santiago; CIC 83: Código de Derecho Canónico, promulgado en 1983 por el papa Juan Pablo II; m.p.: motu proprio; scat.: scatola, caja.

1 m.p. Arduum sane munus, en ASS. Vol. 36 (1903-1904), 549-551. El m.p. lleva la fecha 14 de abril de 1904, pero parece que se trata de un error de imprenta, pues en la carta circular Pergratum mihi, fechada el 25 de marzo de 1904, hay una referencia expresa al m.p. Arduum sane munus. Son de esta opinión Joaquín Llobell, Enrique de León y Jesús Navarrete, Il libro "De processibus" nella codificazione del 1917. Studi e documenti, Milano, Giuffré, 1999, tomo I, 34, n. 30.

2 La nómina de sus integrantes en ASS. Vol. 36 (1903-1904), 551.

3 Antiguo profesor en el Instituto Católico de París, entonces arzobispo titular de Cesarea y secretario de la Congregación de Asuntos Eclesiásticos Extraordinarios, a quien se le nombró al mismo tiempo presidente de la Comisión de Consultores. Posteriormente sería hecho cardenal.

4 En la decisión cuarta, el Papa manifestaba su deseo de que todo el episcopado, conformándose a las reglas que serían dadas en tiempo oportuno, colaboraran y concurrieran a esta obra tan importante: "IV. Volumus autem universum episcopatum, iuxta normas opportune tradendas, in gravissimum hoc opus conspirare atque concurrere". Arduum sane munus, op. cit.

Circular Pergratum mihi, en ASS. Vol. 36 (1903-1904), 603-604. 
católica ${ }^{6}$. La respuesta de los obispos fue amplia, contándose la de numerosos obispos latinoamericanos, incluidos los chilenos. Se calcula en aproximadamente cinco mil el número de personas que fueron consultadas, por lo que, no sin razón, se ha dicho que el trabajo de consulta a los obispos fue como un concilio ecuménico por correspondencia ${ }^{7}$.

El numeroso material reunido fue sistematizado según la estructura que se había definido en el índice de materias fijado por los cardenales mientras se hacía la consulta, y reproducido en un volumen que permaneció inédito, bajo la dirección del consultor Bernardino Klumper, con el título Postulata Episcoporum in ordine digesta ${ }^{8}$. Posteriormente se agregó un segundo volumen, más breve que el anterior, con solo 68 páginas, impreso en 1908 con el título Appendix ad Postulata Episcoporum, reproducido igualmente por Bernardino Klumper ${ }^{9}$, en el que probablemente se recogen las respuestas llegadas con retraso, cuando el primero de estos volúmenes ya estaba en prensa. Ninguno de los dos volúmenes llegó a empastarse y su circulación quedó estrictamente restringida a los consultores, de manera que no fueron conocidos fuera de ese círculo. Preciso es tener presente, sin embargo, que no todos los postulata fueron recogidos por Klumper, si bien la mayoría lo fue; de ellos, el consultor fue recogiendo lo que consideraba de utilidad o cambiando de lugar las sugerencias iniciales, por lo que la consulta a los documentos originales se hace indispensable para poder conocer con precisión lo sugerido por los obispos ${ }^{10}$.

Como ha sido puesto de relieve, estos postulata reflejan el sentir del episcopado mundial en lo que se refiere a la codificación y permiten conocer cuáles eran las preocupaciones y los problemas que les interesaban a inicios del siglo XX, no solo de orden jurídico, sino también eclesiástico, disciplinar, pastoral, etc. ${ }^{11}$; desde esta perspectiva, los postulata constituyen una útil manera de aproximarse a las realidades de las iglesias locales de la época, a partir de unos protagonistas tan directos como los obispos de cada una de ellas. En ellos se solicitan y sugieren soluciones que, en no pocos casos, solo fueron adoptadas por el Concilio Vaticano II y el Código de Derecho Canónico de 1983.

6 Como se ha observado, se solicitó la colaboración del Episcopado para que los consultores, con frecuencia hombres más bien teóricos, fuesen iluminados acerca de las condiciones de vida particular de los diferentes países; la consulta era necesaria para asegurar que el nuevo código tuviese un carácter eminentemente práctico y para que, gracias a las sugerencias de los obispos, se eliminasen todas las imperfecciones del derecho vigente, introduciéndole al mismo tiempo las reformas necesarias. Adam Vetulani, "Codex Juris Canonici", en Dictionnaire de Droit Canonique, París, Letouzey et Ané, 1942, tomo III, col. 920.

7 Otra circular, esta vez de 6 de abril de 1904, atribuible al secretario de la Comisión, Pedro Gasparri, fue dirigida a los rectores de las universidades católicas para pedirles el concurso "en esta empresa importante y difícil”. Circular Perlegisti, en ASS. Vol. 37 (1904-1905), 130-131.

8 Codex Iuris Canonicil Postulata Episcoporum/ in ordinem digestal al Rmo. P. Bernardino Klumper O.F. M./ Consultore/ Romael Typis Vaticanis/ 1905/ 283 , en ASV. CIC 17, scat. 4.

9 Appendix ad Postulata Episcoporum, en ASV. CIC 17, scat. 6.

10 Al no estar todavía generalizado el uso de la máquina de escribir, la mayoría de los postulata son manuscritos, lo que dificulta su lectura, a lo que hay que agregar el hecho de que están escritos en diversas lenguas, porque no todos los obispos usaron el latín para sus respuestas, si bien un número importante usó la lengua oficial de la Iglesia. 


\section{LOS PROTAGONISTAS CHILENOS}

\section{Arzobispo y obispos}

En marzo de 1904 había en Chile un arzobispado y tres obispados: el arzobispado de Santiago ${ }^{12}$ y los obispados de Concepción ${ }^{13}$, San Carlos de Ancud ${ }^{14}$ y La Serena ${ }^{15}$. El arzobispo de Santiago era Mariano Casanova Casanova (1886-1908); el de Concepción, Plácido Labarca Olivares (1890-1905); el de San Carlos de Ancud, Ramón Ángel Jara Ruz (1898-1909); y el de La Serena, Florencio Fontecilla Sánchez (1890-1909). Tan solo ellos tenían derecho a intervenir en un concilio provincial y, por lo mismo, solo a ellos era preciso escuchar antes de responder a Roma, tal como estaba señalado en la circular enviada por el Secretario de Estado. De ellos, eran Mariano Casanova y Ramón Ángel Jara quienes tenían una mayor formación y experiencia jurídica.

En efecto, el arzobispo Casanova ${ }^{16}$ no solo había recibido una buena formación jurídica, que había proyectado como docente ${ }^{17}$, sino que al momento de abordar la respuesta a Roma acumulaba una amplia experiencia como legislador, al haber llevado adelante el Sínodo de Santiago de $1895^{18}$ e impulsado el Concilio Plenario

11 Llobell, De León y Navarrete, op. cit., 47-48.

12 Pío IV (1559-1565) creó el obispado de Santiago el 27 de junio de 1561 por la bula Super specula; su texto en Fernando Retamal Fuentes (compilador), Chilensia Pontificia. Monumenta Ecclesiae Chilensia, Santiago, Ediciones Universidad Católica de Chile, 1998, Vol. I, tomo 1, 4-9. Gregorio XVI (1831-1846) erigió el arzobispado de Santiago el 23 de junio de 1840, mediante la bula Beneficentissimo divinae providenciae consilio. Su texto en ibid., 274-283. La bula está fechada "a los doce días de las calendas de junio" de 1840, día que corresponde al 21 de mayo de ese año, aunque, por lo general, se ha indicado como fecha el 23 de junio de 1840 .

13 Pío IV creó el obispado de Concepción el 22 de marzo de 1563, mediante la bula Super specula. Su texto en ibid., 34-39.

14 Gregorio XVI creó el obispado de San Carlos de Ancud el 1 de julio de 1840, mediante la bula Ubi primum. Su texto ibid., 294-305.

15 Gregorio XVI creó el obispado de La Serena el 1 de julio de 1840, mediante la bula $\mathrm{Ad}$ apostolicae potestatis fastigium. Su texto en ibid., 284-293.

16 Fidel Araneda Bravo, Historia de la Iglesia en Chile, Santiago, Paulinas, 1986, 592-620; y "Mariano Casanova", en La Revista Católica, año 57, № 981, Santiago, mayo-agosto de 1958, 20302048; Crescente Errázuriz, Algo de lo que he visto, Santiago, Nascimento, 1934, 351-473; Virgilio Figueroa, Diccionario histórico biográfico y bibliográfico de Chile 1800-1928, Santiago, Balcells, 1928, tomo II, 377-378; Óscar Larson, "Recordando a Mons. Casanova", en La Revista Católica, tomo 54, año 28, N 636, Santiago, 19 de mayo de 1928, 660-664; Carlos Oviedo Cavada, Los obispos de Chile, Santiago, Editorial Andrés Bello, 1996, 91-92; Francisco Padilla, Monseñor Mariano Casanova, un precursor de los Pactos de Mayo, Córdoba, Imprenta de la Universidad, 1958; Luis Francisco Prieto del Río, Diccionario biográfico del clero secular de Chile 1535-1918, Santiago, Imprenta Chile, 1922, 187-189; Julio Retamal Ávila, Monseñor Mariano Casanova, 1886-1908. Tercer arzobispo de Santiago, Santiago, Salesiana, 1981.

17 Hizo sus primeros estudios en el Instituto Nacional y posteriormente en el Seminario Conciliar. En el Seminario fue primero inspector y más tarde catedrático de Derecho y Ciencias Eclesiásticas hasta 1868. También fue profesor en el Instituto Nacional, donde desempeñó las cátedras de Filosofía y Fundamentos de la fe. Se ordenó sacerdote el 20 de septiembre de 1856, incardinándose en el clero de Santiago. En 1859 fue elegido miembro académico de la Facultad de Teología de la Universidad de Chile; y al año siguiente, 1860, se tituló de abogado.

18 En 1895 celebró el VII Sínodo de Santiago, asamblea que no se realizaba desde 1763, producto del cual resultó un texto con 1.888 artículos, que representó el fundamento moral y jurídico de la 
Latinoamericano ${ }^{19}$, y como pastor, al conducir la más importante de las diócesis chilenas. Por su parte, Ramón Ángel $\mathrm{Jara}^{20}$ tenía formación jurídica general y canónica en particular, al punto de haberse desempeñado como profesor de Derecho Canónico en la recién creada Universidad Católica. A ello se agregaba su experiencia como obispo, si bien todavía breve, dignidad con la cual había participado con los demás obispos chilenos en el Concilio Plenario Latino Americano. Con todo, tenía una buena formación jurídica que volcaría poco después, al celebrar en 1907 el Tercer Sínodo de Ancud, cuya preparación inició precisamente al año siguiente de haber respondido la circular de la Santa Sede.

A diferencia de los anteriores, Plácido Labarca ${ }^{21}$, que contaba con 66 años al momento de recibirse en Chile la circular del Secretario de Estado y que moriría al año siguiente, no había tenido mayor formación jurídica, salvo la enseñanza general que acerca de los cánones se recibía en el seminario. Tenía, sin embargo, la cercana experiencia del Concilio Plenario Latinoamericano. Algo similar sucedía con Florencio Fontecilla ${ }^{22}$, si bien cuando en 1904 tuvo que enfrentarse a la circular romana, además de tener la experiencia de participar en el Concilio Plenario Latino Americano, tenía una amplia experiencia pastoral desarrollada en situaciones difíciles, en las que el derecho canónico debió estar permanentemente presente. Esa sensibilidad por lo jurídico lo llevó a plantear primero, y zanjar después para el futuro, el tema del juramento civil de los obispos ${ }^{23}$. Con todo,

Iglesia de Chile: Sínodo diocesano celebrado en Santiago de Chile por el Iltmo. y Rmo. Señor arzobispo Dr. D. Mariano Casanova, Santiago, Imprenta Roma, 1896: el volumen incluye el texto del Sínodo Diocesano (680 páginas) y "Apéndice del Sínodo Diocesano" (119 páginas). Posteriormente fueron publicadas las Fuentes del Sínodo diocesano celebrado en Santiago de Chile por el Illmo. y Rmo. Señor arzobispo Dr. D. Mariano Casanova del 8 al 15 de setiembre de 1895, Santiago, Imprenta de la Revista Católica, 1903, 247

19 Había propuesto al papa León XIII, en 1888, la celebración de un concilio de todos los arzobispos y obispos de la América Meridional, del cual fue su principal impulsor. Pedro Gaudiano, "Presidentes, relatores y miembros del Concilio Plenario de América Latina", en Pontificia Commissio pro America Latina, Los últimos cien años de la evangelización en América Latina. Centenario del Concilio Plenario de América Latina. Actas, Ciudad del Vaticano, Librería Editrice Vaticana, 2000, 746-747; Misael Camus Ibacache, "La preparation et la convocation du Concile Plénier d'Amerique Latine célébré à Rome en 1899”, en Revue d'histoire ecclésiastique, Vol. 93, Lovaina, 1998, 66-82.

20 Araneda, op. cit., 646-651 y 680-681; Oviedo, op. cit., 145-147; Prieto, op. cit., 343-344.

21 Araneda, op. cit., 628-629; Figueroa, op. cit., tomo III, 609; Oviedo, op. cit., 148-149; Prieto, op. cit., 353 .

22 Araneda, op. cit., 640-644; Oviedo, op. cit., 121-122; Prieto, op. cit., 252-253.

23 Uno de los primeros problemas que debió abordar al ser nombrado obispo fue el juramento civil de los obispos, que el beato Pío IX (1846-1878) había rechazado por considerar que la fórmula conculcaba los derechos de la Iglesia. El nuevo obispo preguntó al presidente Balmaceda si el juramento civil que debía prestar no estaría reñido con la doctrina y la autoridad de la Iglesia; y al ministro de relaciones exteriores y culto, José Tocornal, le pidió que le aclarara si, a juicio del Gobierno, podría el juramento obligarlo a contradecir, en algún caso, la doctrina y la autoridad de la Iglesia. Ambos respondieron entendiendo que el juramento constitucional en ningún caso podría obligarlo a contrariar la doctrina de la Iglesia, de manera que, como obispo, no podría obrar en ninguna circunstancia en contra de la ley de Dios o de la autoridad de la Iglesia. Quedaba así claro que el juramento de observar y hacer observar la Constitución de la república no se extendía a aquello que fuese en detrimento de la doctrina o de la autoridad de la Iglesia. Poco después, el cardenal Rampolla, secretario de Estado de Su Santidad, le contestaba al obispo Fontecilla que "nada resta que hacer al nuevo obispo, sino declarar, cuando sea oportuno, al clero y al pueblo que ha prestado juramento sin perjuicio de las leyes divinas y eclesiásticas". En Retamal Fuentes, op. cit., vol. 2, tomo I, 412-413. 
moriría poco tiempo después, en La Serena, el 1 de marzo de 1909, cuando tenía 55 años de edad.

\section{Colaboradores}

Una vez que llegó a manos del arzobispo Casanova la circular Pergratum mihi, de la Secretaría de Estado, del 25 de marzo de 1904, formulando la primera consulta al episcopado latino ${ }^{24}$, el metropolitano nombró una comisión ${ }^{25}$ integrada por cinco sacerdotes que le ayudarían en la elaboración de la respuesta. Ellos fueron los presbíteros Alberto Vial y Carlos Silva Cotapos y los religiosos fray Raimundo Errázuriz (o.p.) y Narciso Sagrega (s.j.), todos ellos presididos por el obispo titular de Epifanía, Rafael Fernández Concha. Tarea de la comisión era "que nos ayuden en tan importante asunto, indicándonos los puntos principales que convenga observar".

Rafael Fernández Concha, a petición del Estado de Chile, había sido nombrado obispo titular de Epifanía por el papa León XIII, siendo consagrado en Santiago, el 2 de junio de 1901, por Mariano Casanova, arzobispo de Santiago. Al no tener derecho a participar en el sínodo provincial ${ }^{26}$, no era preciso tomar su parecer; sin embargo, por ser este uno de los clérigos más cultos en materias jurídicas ${ }^{27}$, el arzobispo Casanova no quiso desaprovechar su colaboración. Él mismo, además, por su cuenta, envió un proyecto de cánones preliminares referidos a la constitución de la Iglesia, las leyes y la jurisdicción ${ }^{28}$.

Alberto Vial y Guzmán ${ }^{29}$, del clero de Santiago, después de estudiar en Chile había estudiado en Roma, perfeccionándose en Teología, materia que enseñó en el

24 Se publicó en el BEAS. Vol. 16 (1904-1907), 153-154 n. 261B.

25 Decreto de 11 mayo 1904, en BEAS. Vol. 16 (1904-1907), 80, n. 129.

26 Justo Donoso, Instituciones de derecho canónico americano, Valparaíso, Imprenta y Librería del Mercurio, 1848, tomo I, 23-24.

27 En el Instituto Nacional había sido alumno de Andrés Bello; fue bachiller en Humanidades y licenciado en Leyes por la Universidad de Chile, en cuya facultad de Leyes enseñó Derecho Canónico; fue autor de diversos libros jurídicos, filosóficos y religiosos. Tuvo una destacada participación en el Sínodo de Santiago de 1895 y en el Concilio Plenario Latino Americano. Enrique Amador Fuenzalida, Galería contemporánea de hombres notables de Chile (1850-1901), Valparaíso, Imprenta del Universo de Guillermo Helfmann, 1901, tomo I, 103-110; Hugo Ayala Godoy, Rafael Fernández. Concha, Memoria, Universidad de Chile, 1947; Fermín Donoso Espic, La filosofía del derecho en Rafael Fernández Concha, Santiago, Editorial Universitaria, 1962 ; Julio Jiménez B, S.J., "En el cincuentenario de don Rafael Fernández Concha", en Revista Mensaje, № 113, Santiago, 1962, 471-477; id., "Las bodas de oro del Ilmo. Sr. Obispo de Epifanía, don Rafael Fernández Concha”, en La Revista Católica, tomo XVIII, año 9, No 205, Santiago, 5 febrero 1910, 80-82; id., "Necrología. El Ilmo. Obispo de Epifanía, doctor don Rafael Fernández Concha", en La Revista Católica, tomo XXIII, año 13, N 269, Santiago, 19 octubre 1912, 757-759; Vicente Ossa Busta, "Presbítero Rafael Fernández Concha. Biografía", en id., La capellanía ante la jurisprudencia eclesiástica. Casos del arzobispado de Santiago, Memoria, Universidad de Chile, 1995, 3-22; Oviedo, op. cit., 120-121; Prieto, op. cit., 241-242; Jorge Quezada Núñez, Juristas chilenos del siglo XIX: Rafael Fernández Concha, Memoria, Universidad de Chile, 1995.

28 Carlos Salinas Araneda, "Un manuscrito inédito del obispo chileno Rafael Fernández Concha: un proyecto parcial de Código de Derecho Canónico presentado con ocasión de la codificación canónica de 1917”, en Revista de Estudios Histórico-Jurídicos, N² 29, Valparaíso, 2007, 481-514.

29 Prieto, op . cit., 709-710. 
Seminario de Santiago desde su regreso a Chile hasta $1902^{30}$. Carlos Silva Cotapos se desempeñaba como secretario del Arzobispado, cuando fue nombrado por el arzobispo Casanova para integrar la comisión que debía asesorarlo en esta primera proposición a Roma, cargo en el que se desempeñaba desde 1902 y en el que permaneció hasta 1914³1. Fray Raimundo Errázuriz Valdivieso había estudiado dos años leyes en la Universidad de Chile, ingresando al Seminario de Santiago y ordenándose sacerdote el 18 de diciembre de 1863. Algunos años después, en 1869 y 1870, acompañó a su tío, el arzobispo de Santiago Rafael Valentín Valdivieso, al Concilio Vaticano I. Entre 1884 y 1911 fue religioso de la Recoleta Domínica, en la que fue varias veces prior. Cuando fue nombrado para incorporarse a esta comisión, era todavía fraile dominico ${ }^{32}$. El último de los colaboradores fue el jesuita Narciso Sagrega.

\section{EL APORTE DE LOS OBISPOS CHILENOS}

\section{Informe del arzobispo Mariano Casanova ${ }^{33}$}

El informe fue enviado por el arzobispo Mariano Casanova con una carta escrita en latín, dirigida al Cardenal Secretario de Estado, fechada en Santiago el 22 de septiembre de $1904^{34}$. En ella le hacía presente que había recibido la circular durante el mes de mayo de 1904 y que había hecho las consultas a los otros tres obispos que tenían derecho a participar en concilio provincial. De ellos, el de La Serena había hecho suyas las proposiciones del arzobispo Casanova, en tanto que el obispo de Ancud y el de Concepción, sin perjuicio de hacer igualmente suyas las observaciones de la comisión, habían hecho llegar por escrito sus observaciones, las que fueron enviadas a Roma conjuntamente con el informe del Arzobispo. Si, como decía Casanova, la circular había llegado en el mes de mayo y su respuesta está fechada el 22 de septiembre, el Arzobispo y sus sufragáneos pudieron responder la consulta dentro del plazo fijado por Roma. El informe del arzobispo Casanova, hecho suyo por los obispos de La Serena y Concepción, lleva en latín el título

30 En 1887 el arzobispo Casanova lo nombró miembro de la comisión encargada de preparar la fundación de la Universidad Católica en Santiago. Escribía artículos sobre cuestiones religiosas, publicados en los diarios católicos del momento, llegando a detentar durante un breve tiempo la dirección del diario El Porvenir. Escribió un libro sobre el clero católico en Alemania, que tuvo tres ediciones, y otro sobre la constitución cristiana del Estado, a propósito de la encíclica Inmortale Dei, de León XIII. Falleció en Santiago el 18 de julio de 1918.

31 Posteriormente, además de su labor académica, como miembro de la Facultad de Teología de la Universidad de Chile, y como historiador, fue nombrado obispo de La Serena (1918-1925) y de Talca (1925-1839), falleciendo el 29 de septiembre de 1941. Oviedo, op. cit., 215-216.

32 Una vez que obtuvo la secularización, con el nombre de Crescente Errázuriz Valdivieso se incorporó al clero de Santiago, arquidiócesis de la que llegaría a ser arzobispo (1918-1931). Falleció en Santiago el 5 de junio de 1931. Oviedo, op. cit., 114-115.

33 Informatio/ Episcopatus Chilensis de rebus/ in Jure Canonico reformandis/ juxta motum proprium Ssmi./ Dni. Nostri Pii Papae X, del Ecclesiae legibus in unum redigendis. Su texto original en ASV. CIC 17, scat. 96. 
que, traducido al castellano, es el siguiente: Información del episcopado chileno sobre las materias que hay que reformar en el derecho canónico según el motu proprio de Nuestro Santísimo Señor el Papa Pío X, De Ecclesiae legibus in unum redigendis. Se trata de un extenso informe de 36 hojas en folio, manuscrito en latín por un solo lado. El contenido del mismo se refiere a aspectos diversos del derecho canónico vigente, distribuidos en 56 párrafos numerados al modo romano, que se siguen unos a otros sin mayor individualización.

Los temas abordados por los obispos son variados: hay sugerencias referidas a las fuentes del derecho canónico, algunas de las cuales se inspiran abiertamente en la experiencia jurídica del derecho del Estado de Chile, como la existencia en la Iglesia de un código fundamental, equivalente a la Constitución Política del Estado, unido a otros códigos canónicos referidos a distintas materias; la publicación de la ley en un boletín oficial destinado a ese efecto; y la vacación de la ley o la supresión de las regula iuris. Otras propuestas apuntan a las tareas y a la disciplina de obispos, clérigos y religiosos. Hay interesantes sugerencias en materia de persona jurídica, siendo el episcopado chileno el único en plantearlas; y existe, finalmente, un número de proposiciones que se refieren a temas canónicos generales, como la posibilidad de dispensar de la exigencia de grados académicos para desempeñar determinados oficios, las elecciones, la nulidad de algunos actos por no cumplirse determinadas exigencias y la extensión de dicha nulidad, aspectos específicos referidos a sacramentos y sacramentales, y otras ${ }^{35}$. De las diversas sugerencias del episcopado chileno, centraremos ahora nuestro análisis solo en las propuestas referidas al matrimonio.

\section{Esponsales}

Sugiere el informe del arzobispo Casanova que, a fin de que se tengan como nulos los esponsales que no se han contraído por escritura pública, habría que decretar y declarar esta escritura, para que nunca y de ningún modo pueda ser sustituida por aquellos escritos que, en Chile, se llamaban "informaciones matrimoniales" o por aquellos por los cuales se pedía una dispensa de impedimentos matrimoniales ( $\$ 39$ ).

Donoso $^{36}$, después de definir los esponsales con la fórmula latina "mutua promissio et aceptatio futurarum nuptiarum" (i.e. mutua promesa y aceptación de futuras nupcias), enumera los requisitos para la validez canónica de los mismos: i) que la promesa sea seria y verdadera; ii) que sea deliberada y exenta de todo miedo grave y error acerca de la persona; iii) que se manifieste con palabras $\mathrm{u}$ otros

34 Su texto en latín se publicó en BEAS. Vol. 16 (1904-1907), 154-155, n. 261C. El original se encuentra en ASV. CIC 17, scat. 96.

35 Para una presentación completa de las sugerencias hechas por los obispos chilenos en esta etapa del proceso codificador, véase Carlos Salinas Araneda, "El primer aporte de los obispos chilenos a la codificación del derecho canónico de 1917: los postulata episcoporum", en Revista de Estudios Historico-Jurídicos, $\mathrm{N}^{\mathrm{o}}$ 30, 2008 (en prensa).

36 Justo Donoso, Instituciones de derecho canónico americano, Valparaíso, 1849, II, 150. 
signos equivalentes; iv) que sea mutua y aceptada por ambas partes; v) que las personas sean hábiles, esto es, que no se hallen ligados con impedimentos dirimentes ni impedientes, y que tengan la edad de siete años requerida por el derecho. Cumplidos estos requisitos, los esponsales eran válidos y, aunque fueran clandestinos, obligaban en conciencia.

Aun cuando, respecto a lo que ahora nos interesa, se exigía que los esponsales se manifestasen con palabras u otros signos equivalentes, no estaba prescrita canónicamente ninguna formalidad especial. La ley civil, en cambio, tanto la heredada de la monarquía española como la ley patria chilena, había establecido la exigencia de la escritura pública. En efecto, una pragmática de Carlos III, del 28 de abril de $1803^{37}$, disponía que "en ningún tribunal eclesiástico ni secular de mis dominios se admitirán demandas de esponsales, sino es que sean celebrados por personas habilitadas para contraer por sí mismas según los expresados requisitos y practicados por escritura pública", caso en el que se procedería como si fueran asuntos puramente civiles. Esta exigencia legal había sido reconocida por la S. Congregación del Concilio en $1880^{38}$, la que, respondiendo una duda, había declarado que "los esponsales celebrados en España sin escritura pública, deben ser considerados nulos".

Una exigencia similar se hacía en la ley patria dictada sobre el matrimonio de los menores, conocida como Pragmática de matrimonio ${ }^{39}$, en la que se podía leer que "ninguna demanda de esponsales de los que no tienen edad para deliberar por sí, se admitirá en los tribunales del Estado, si no ha precedido el consentimiento de los padres o personas autorizadas para ello en un instrumento público y fehaciente". El Código Civil (1855), sin embargo, cambió radicalmente la disciplina al disponer que los esponsales "o sea la promesa de matrimonio mutuamente aceptada, es un hecho privado, que las leyes someten enteramente al honor y conciencia del individuo, y que no produce obligación alguna ante la ley civil" (art. 98, inc. $1^{\circ}$ ).

A pesar de que la norma negaba todo valor a los esponsales en el fuero civil, ellos seguían existiendo en el fuero canónico, por lo que el arzobispo Casanova, en 1894, solicitó a la S. Congregación del Concilio que se extendiera a la arquidiócesis de Santiago la vigencia de la respuesta dada en 1880 para los esponsales celebrados en España ${ }^{40}$. El sínodo del arzobispado de Santiago, celebrado por Mariano Casanova al año siguiente, en 1895, nada dijo sobre el particular, salvo alguna norma de carácter general, con un fin más bien moralizador, que se hacía eco del

37 "Real cédula sobre matrimonios de hijos de familias", recogida en la Novísima recopilación, Libro X, Título II, Ley XVIII. También en Gonzalo Vial, "Aplicación en Chile de la pragmática sobre matrimonio de los hijos de familia", en Revista Chilena de Historia del Derecho, № 6, Santiago, 1970, 335-362.

38 Su texto en Retamal Fuentes, op. cit., II-2, 634-645.

39 Art. 19 ley de 9 septiembre 1820, Pragmática de matrimonios, en BL. 1846, 158-167. Carlos Salinas Araneda, "Algunas consideraciones sobre el matrimonio en la legislación civil de Chile antes del Código Civil (1810-1857)", en Gustavo Pinard y Antonio Merchán, Libro homenaje in memoriam Carlos Díaz Rementería, Huelva, Universidad de Huelva, 1998, 644-653.

40 Su texto en Retamal Fuentes, op. cit., II-2, 644-645. 
Código Civil, cuando encargaba a los párrocos y confesores que procuraran "que las mujeres del pueblo sepan que en ningún caso tienen acción ante los jueces civiles para pedir el cumplimiento de la promesa de matrimonio, a fin de evitar en lo posible que por medio de esa promesa se las seduzca para consentir en el pecado" (art. 1586). En cambio, el Concilio Plenario Latinoamericano abordó el tema expresamente, al punto de que pareció necesario a los padres conciliares, quizá inspirados por Casanova, solicitar al papa León XIII la extensión a América Latina de la declaración que, para España, había dado la S. Congregación del concilio el 31 de enero de 1880, es decir, pedir que se extendiera para todo el continente lo que Casanova había pedido para su arquidiócesis, a saber:

"los esponsales en nuestras provincias, son inválidos, si no se contraen mediante escritura pública, a cuya escritura no pueden suplir las informaciones matrimoniales, ni las diligencias practicadas en la curia diocesana, o en otra parte, con el fin de obtener la dispensa de algún impedimento, aunque de ellas se infiera la promesa formal de contraer matrimonio".

Esta petición conciliar fue benignamente acogida por el Romano Pontífice, quien, por decreto de la S. Congregación de Asuntos Eclesiásticos Extraordinarios del 1 de enero de $1900^{41}$, concedió la extensión solicitada, de la que se dejó expresa constancia en las actas del Concilio ${ }^{42}$. Nos parece que ha sido esta norma vigente en España, recogida por el Concilio Plenario Latinoamericano y quizá motivada por el propio arzobispo Casanova, la que ha inspirado inmediatamente a los obispos chilenos, si bien ella venía a materializar una práctica que había estado vigente en Chile durante largos años, por disponerlo así la ley civil, y que ahora estaba vigente en el fuero canónico, por la extensión hecha por León XIII.

Los obispos chilenos no fueron los únicos en solicitar una formalidad especial para los esponsales, pues otros episcopados se refirieron al mismo tema, si bien sugerían otras formalidades, como que obligaran solo cuando estuvieran por escrito $^{43}$, o que se celebraran ante el párroco y dos testigos ${ }^{44}$ o en otra forma pública determinada $^{45}$. Los obispos chilenos postularon la celebración de los mismos por escritura pública, coincidiendo con otros episcopados, como los de la provincia eclesiástica de Burgos en España, donde la escritura pública era exigencia vigente, e incluso con algunos donde dicha exigencia, al parecer, no existía, como los de Ruan, Lyon y Arras en Francia ${ }^{46}$.

El Código de Derecho Canónico dispuso que la promesa de matrimonio, tanto la unilateral como la bilateral o esponsales, era nula en ambos fueros "si no se hace por medio de escritura firmada por las partes y además por el párroco u ordinario

41 Su texto en ibid., 952-953.

42 Concilio Plenario de América Latina, 592 n. 1.

43 Los obispos sardos. Codex..., op. cit., 140.

44 Los arzobispos de Acerenza y Matera. Idem.

45 Los obispos de la región de Benevento; padres de la provincia de Tours, en Francia. Idem.

46 Ibid., 141. 
del lugar, o al menos por dos testigos" (can. 1.017 § 1). Es decir, dispuso una formalidad expresa para la validez de los esponsales, con lo cual se hacía eco de las peticiones hechas en este sentido; pero no llegó a exigir una escritura pública como lo sugerían los obispos chilenos, ya que esta proposición, al contemplar que la escritura pública se extendiese ante una autoridad estatal y no eclesiástica, no estaba exenta de un cierto sabor regalista. Por otra parte, la doctrina de la Iglesia como sociedad jurídicamente perfecta, sostenida por esos años por el derecho público eclesiástico, no favorecía la recepción de una solución como la postulada por los obispos chilenos ${ }^{47}$.

\section{Información matrimonial para matrimonio entre católicos}

Para simplificar las formas, parecía conveniente, según el informe del arzobispo Casanova, reducir lo que estaba ordenado acerca de las investigaciones que había que hacer antes del matrimonio, llamadas en Chile "informaciones matrimoniales", en las que se probaba la facultad de los novios para contraer matrimonio $(\S 40)$.

El tema había sido amplia y minuciosamente tratado en el Sínodo de Santiago de 1895, el que le dedicaba nada menos que treinta artículos (arts. 1617-1646), que se iniciaban con la solemne afirmación de que no se procedería al matrimonio sin que, por medio de la información prescrita por los cánones, se hubiese acreditado la soltería y la habilidad de los contrayentes (art. 1.617). Para ello, disponía dónde debía hacerse la información si se hacía en Santiago (art. 1.618) o fuera de dicha ciudad (art. 1.619), los elementos de que debía constar (art. 1.620), el contenido del pedimento del novio cuando él y la novia eran hijos legítimos (art. 1.621), cuando no lo eran (art. 1.622), cuando era viudo (art. 1.623), o cuando había que solicitar la dispensa de algún impedimento (art. 1.624), para lo cual había que instruir al novio en los impedimentos, pedimento que debía firmar en un acta, cuyo texto se incluía (art. 1.627). Una vez provisto el pedimento, se procedía a inquirir la voluntad de la novia, procurando que gozase de completa libertad, sustrayéndola de toda coacción y causa de miedo (art. 1.628), diligencia que era muy importante, por lo que solo por grave y extraordinaria causa podía dejarse para después de otras diligencias o al fin de la información (art. 1.629). Hecho lo anterior, si el novio o la novia eran menores, se debía tomar "el consentimiento" de los ascendientes o curadores, según las reglas que el mismo Sínodo establecía (arts. 16301631); para seguir después con las declaraciones de los testigos, que debían ser consultados al tenor de la preguntas que detalladamente se contenían (art. 1.632).

Cumplidas las diligencias anteriores, y habiendo resultado probada la habilidad de los novios, debía dictarse el auto que mandaba expedir la boleta para el párroco respectivo, si la información se hacía en la curia, o que mandaba simplemente proceder al matrimonio, previas las proclamas, si la información la hacía algún

47 Rafael Fernández Concha, Derecho público eclesiástico, Santiago, Imprenta del Correo, 1872, 2 vols., passim. 
cura vicario y no era el caso de elevar el expediente al obispo para dispensa de impedimentos o consulta (art. 1.633).

Los casos que requerían consulta estaban definidos de la siguiente manera (art. 1.634): i) el matrimonio de los viudos cuando la viudez no estaba claramente probada por los medios que se indicaban; ii) el matrimonio de los extranjeros, toda vez que no probaren su soltería con instrumentos auténticos del ordinario de su lugar y con testigos que los conociesen al menos por tiempo de diez años; iii) el matrimonio de los vagos, a menos que hubiesen vivido como tales solo dentro del pueblo o lugar del matrimonio. En todos estos casos, además de la consulta, la información debía hacerse con las cautelas que el mismo Sínodo se encargaba de prescribir (arts. 1635-1636).

Sin la previa información escrita no podía celebrarse ningún matrimonio, salvo urgencia en artículo de muerte, en cuyo caso la información se practicaría verbalmente $\mathrm{y}$, tan pronto como se verificase el matrimonio, se reduciría a un acta escrita en la forma antes mandada (art. 1.639). En todas estas diligencias había que actuar con notario o dos testigos, salvo en la declaración de voluntad de la novia, que podía tomarse sin dicho auxilio (art. 1.640). Las últimas disposiciones dan normas sobre los registros (arts. 1642-1646).

Como puede advertirse, las normas sinodales eran minuciosas, y en ellas se recogían y hacían operativas no solo normas canónicas generales, sino también las de sínodos chilenos anteriores, doctrina de autores y la misma práctica de la Iglesia chilena $^{48}$. La simplificación de las mismas era lo que se pedía en el informe del arzobispo de Santiago.

El Código de 1917 dedicó un título completo a "las cosas que deben preceder a la celebración del matrimonio y en especial de las proclamas matrimoniales", que, al igual que había ocurrido en el sínodo santiaguino, se iniciaba con la afirmación de que "antes de celebrar el matrimonio debe constar que no hay nada que se oponga a la validez y licitud de su celebración" (can. $1.019 \S 1$ ), razón por la que el párroco a quien correspondía el derecho de asistir al matrimonio "debe indagar diligentemente, con tiempo oportuno, si hay algo que impida el contraerlo" (can. $1.020 \S 1$ ), interrogando, por separado y con cautela, al esposo y a la esposa, "acerca de si están ligados por algún impedimento, si prestan libremente su consentimiento, especialmente la mujer, y si están suficientemente instruidos en la doctrina cristiana" (can. $1.020 \S 2$ ).

El parecido que presentan el derecho chileno sinodal y el derecho codificado en esta materia se explica en el hecho de que ambos se inspiran en el patrimonio jurídico que la Iglesia había desarrollado con anterioridad. La intención de san Pío $\mathrm{X}$, al momento de dar inicio a la tarea codificadora del derecho canónico, no había sido otra que la de reunir en un solo libro, de manera fácilmente asequible, el derecho por entonces vigente, con las reformas que se entendieran necesarias. Sobre este tema no habían parecido necesarias mayores reformas, y en el tema preciso que preocupaba a los obispos chilenos, esto es, la simplificación de las

48 Fuentes del sínodo..., op. cit., 160-161. 
informaciones matrimoniales, el Código se limitó a disponer que "al ordinario del lugar le toca dar normas peculiares para hacer esta investigación del párroco" (can. 1.020 § 3). Con ello, si bien Roma no asumía la tarea de simplificar las diligencias de información matrimonial, facilitaba dicha simplificación, al entregar a cada ordinario la regulación de esta materia.

\section{Información matrimonial de matrimonio de extranjeros}

Cuando se trate de matrimonios entre extranjeros o de un extranjero con alguno del lugar, entendía el informe del Arzobispo que debía definirse lo que fuese justo y conveniente, para lo cual daba las siguientes razones: $1^{\circ}$ La mayor facilidad y frecuencia con la que se producía, a comienzos del siglo XX, la emigración de muchos de una región a otra. $2^{\circ}$ La incuria y negligencia en que caían, casi todos los emigrantes, en proveerse de documentos que pudiesen probar que no estaban unidos a nadie en matrimonio en los lugares en los que alguna vez habían morado. $3^{\circ}$ La facilidad y proclividad de no pocos de estos emigrantes de contentarse con un matrimonio civil o bien de vivir en concubinato. $4^{\circ} \mathrm{La}$ facilidad y frecuencia con que ellos presentaban testigos falsos que juraban en falso que eran célibes o bien viudos (\$ 40).

El tema, inédito en Chile durante el período indiano, había surgido después de la Independencia, con la llegada de extranjeros en número creciente, con la consiguiente dificultad de obtener una información segura acerca de la habilidad de los mismos para contraer matrimonio, precisamente por las dificultades que los obispos ponían de relieve. Es por esto que el sínodo santiaguino de 1895 había dispuesto que, en el caso de matrimonios de extranjeros, debía consultarse al obispo, a fin de recabar su aprobación o licencia para el matrimonio, "toda vez que no probaren su soltería con instrumentos auténticos del ordinario de su lugar y con testigos que los conozcan a lo menos por tiempo de diez años" (art. 1.634, $\mathrm{n}^{\circ} 2$ ). Además, en este tipo de matrimonios, junto con el de los viudos y de los vagos, debía tenerse presente la carta del Cardenal Secretario de Estado del 10 de junio de $1893^{49}$, la instrucción de Clemente X de $1670^{50}$ y la del Santo Oficio de $1868^{51}$ (art. 1.635). $\mathrm{Y}$ en todos estos casos, el encargado de hacer la información, antes de proceder, debía imponerse de las dificultades que ella podía presentar, a fin de consultar o pedir instrucciones al prelado y de no obrar en vano o aumentar las diligencias con daño o molestia de los contrayentes (art. 1.636). Nada dijo sobre esta materia el Concilio Plenario Latinoamericano.

49 Su texto en el "Apéndice del Sínodo Diocesano", anexo VII § II A, 91-92. En ella se lee: "Por lo tanto, tratándose del estado de libertad de los extranjeros que en esa diócesis quieran contraer matrimonio, no se contente Vuestra Grandeza con los testigos, sino que, para alejar a los malos del peligro de poligamia, procure con toda diligencia y antes de conceder el permiso de celebrar el matrimonio, que los contrayentes presenten documentos de su estado de libertad, claros, indudables y exentos de todo fraude, y principalmente documento escrito de la Curia de su propia diócesis".

50 Su texto en ibid., anexo VII § II B, 92-96.

51 Su texto en ibid., anexo VII § III, 96-101. 
El Codex tampoco dijo nada en especial sobre este tema, salvo la norma genérica del canon 1032, referida al matrimonio de los vagos, matrimonio al que el párroco no podía asistir sin antes haber llevado el asunto al ordinario del lugar o a un sacerdote delegado suyo y haber obtenido licencia para asistir al matrimonio; según el canon 91, se entendía por vago aquel que "no tiene en parte alguna domicilio ni cuasidomicilio". Una instrucción posterior de la S. Congregación para la Disciplina de los Sacramentos vino a clarificar el tema, refiriéndose expresamente al matrimonio de los emigrantes ${ }^{52}$; según ella, el matrimonio de los emigrantes era un verdadero matrimonio de vagos, por lo que los párrocos debían poner un cuidado especial y ser más exigentes en las pruebas del estado de libertad y en requerir el certificado de bautismo, debiendo enviar todos los documentos a través de la curia diocesana, además de que debía cumplirse lo exigido por el canon 1032 en cuanto a obtener, antes del matrimonio, la autorización del ordinario.

\section{Investigaciones para dispensa de matrimonio con disidentes}

Según el informe del arzobispo de Santiago (§ 41), la mayoría de las dispensas que se concedían para la celebración de un matrimonio entre católicos y disidentes originaban muchas dudas difíciles de solucionar en las curias eclesiásticas: siempre había que averiguar si el disidente había recibido el bautismo o no; y, si había recibido el bautismo, si este era válido o nulo. Es por esto que se preguntaba acerca de la conveniencia de que dichas investigaciones se derogasen. Si la respuesta fuere afirmativa, entendía que parecía necesario: i) definir quiénes eran disidentes o quiénes habían de ser tenidos como tales; ii) declarar que se incluyese en la dispensa de disparidad de culto si acaso el disidente no fue bautizado o el bautismo fue nulo.

La llegada de extranjeros a Chile, a partir de la Independencia, que no siempre profesaban la religión católica, había hecho surgir el problema de los matrimonios de católicos con quienes no profesaban la misma religión, problema que se extendió cuando los propios chilenos empezaron a adscribirse a las nuevas confesiones religiosas llegadas a Chile. Como escribía Donoso a mediados del siglo XIX, si bien ninguna ley general irritaba este tipo de matrimonios, la Iglesia siempre los había considerado ilícitos y los había prohibido ${ }^{53}$. Con todo, el Papa podía dispensar esta prohibición bajo ciertas condiciones, que Benedicto XIV había expuesto en la constitución Magnae nobis, dirigida en 1748 a los obispos de Polonia, que, en síntesis, consistían en que se pusieran todas las cautelas para que el cónyuge católico no cayera en el error y tratara de sacar de él al otro contrayente; y que la prole de ambos sexos fuese educada en la religión católica.

52 Instructio ad Rev.mos ordinarios locorum super probatione status liberi ac denuntiatione initi matrimonii, 4 de julio 1921, en AAS. Vol. 13 (1921), 348-349. También en Xaverius Ochoa, Leges Ecclesiae post Codicem iuris canonici editae, tomo I: Leges annis 1917-1941, Roma, Ediurcla, 1966, col. 390-391.

53 Donoso, op. cit., II, 179. 
El tema de los matrimonios mixtos no había sido fácil en Chile, especialmente por la oposición que a ellos había hecho el arzobispo Valdivieso ${ }^{54}$. Con todo, la forma de actuar, especialmente cuando el matrimonio era con un católico que, habiendo abandonado su fe, se había adscrito a otra confesión, había quedado fijada en una carta del cardenal Patrizi, secretario de la S. Congregación de la Suprema y Universal Inquisición, del 24 de diciembre de 1871, según la cual, en estos casos había que solicitar la dispensa acostumbrada con las habituales prescripciones y cláusulas conocidas ${ }^{55}$.

El Sínodo de Santiago de 1895 había dispuesto que, "sin especial y competente autorización", los párrocos no podían proceder a la celebración de un matrimonio cuando una de las partes contrayentes profesaba la religión católica y la otra no, "aunque esta última haya sido bautizada en la Iglesia católica y no se haya adherido después a alguna comunión disidente" (art. 1.662). Se limitaba simplemente a repetir la norma general sin entrar en mayores detalles, a diferencia del Concilio Plenario Latinoamericano, que, si bien no había abordado el tema propuesto en el informe santiaguino, era más explícito, pues en él no solo se afirmaba que la dispensa solo podía darla el Romano Pontífice o aquellos autorizados por él, sino que también se explicitaban las condiciones necesarias para obtener dicha dispen$\mathrm{sa}^{56}$, además de prohibirse la celebración del matrimonio, aun concedida la dispensa, "si los novios tienen intención de presentarse, antes o después, a un ministro no católico".

De esta manera, la posibilidad de realizar dichos matrimonios y la forma de hacerlo estaba resuelta por el derecho. Lo que suscitaba las dudas de las curias, cuando había que hacer las respectivas informaciones matrimoniales, era aclarar el tema del bautismo de la parte no católica y, si el bautismo existía, saber si el mismo era válido o nulo. Es por lo que se pedía derechamente eliminar esta parte de la investigación que había que hacer antes del matrimonio; por ello era que se solicitaba definir quiénes eran disidentes o quiénes debían ser tenidos por tales, lo que se complementaba con la inclusión, en la dispensa del impedimento, de la declaración de que la misma se concedía aunque la parte no católica no fuese bautizada o el bautismo fuese nulo. Aceptadas estas dos condiciones, ya no era necesario hacer la previa investigación acerca del bautismo del no católico.

Los obispos chilenos fueron los únicos que hicieron esta sugerencia a la comisión codificadora, pero ella no fue tomada en cuenta, pues el Código de Derecho Canónico nada dijo sobre el tema particular abordado en la propuesta de los obis-

54 Valdivieso explica su actitud en esta materia, en una carta al cardenal Antonelli, del 14 de agosto de 1855. Véase su texto en Retamal Fuentes, op. cit., vol. I, tomo 3, 1168-1171.

55 Su texto en ibid., 1198-1201. También en "Apéndice del Sínodo diocesano", op. cit., Anexo VII $\S 4,101-102$.

56 "El ordinario no podrá conceder la dispensa de manera alguna, si no es con la expresa condición de tomar de antemano las precauciones oportunas y necesarias, para que no solo el cónyuge católico no pueda ser pervertido por el otro, sino para que sepa que está obligado a procurar, con todas sus fuerzas, apartar a su consorte del error; y sobre todo, para que toda la prole de ambos sexos, que resulte de estos matrimonios mixtos, se eduque en la santidad de la religión católica". Concilio Plenario de América Latina, norma 591. 
pos chilenos. En todo caso, el matrimonio de un católico con quien no lo es, era un tema importante y, por lo mismo, el código aprobado lo abordó ${ }^{57}$. Pero la propuesta de los obispos chilenos no se refería a la posibilidad de dichos matrimonios, materia ya regulada por el derecho entonces vigente, sino a la dificultad, más bien administrativa, de averiguar la existencia o validez del bautismo de los disidentes.

\section{Eliminación de algunos impedimentos dirimentes}

Parecía conveniente, decía el informe, una madura reflexión sobre la conveniencia de eliminar algunos impedimentos dirimentes (\$ 42).

i) parentesco espiritual: la relación de parentesco espiritual fue más antigua que el impedimento, el que fue introduciéndose, como sucedió con otros impedimentos, por la costumbre y por algunas disposiciones legislativas particulares, hasta que alcanzó carácter universal. De hecho, en las Decretales (1234) se resuelven algunas dudas que suponen la vigencia del impedimento, el que suscitaba problemas por la variedad de situaciones que lo configuraban, agravados por la multiplicidad de padrinos. El Concilio de Trento fijó en dos el número de padrinos y redujo la figura del impedimento a la paternidad espiritual, esto es entre bautizante y bautizado y entre padrino y bautizado, y a la compaternidad, o sea, entre los padres del bautizado y el bautizante y padrinos ${ }^{58}$.

Donoso $^{59}$ explicaba que se trataba de un impedimento de derecho eclesiástico y, por lo mismo, dispensable, y que dirimía el matrimonio en las siguientes situaciones: i) entre el bautizante y bautizado y padre y madre de este; ii) entre los padrinos y el bautizado, y el padre y madre del mismo; iii) entre el confirmante y el padrino o madrina de confirmación, por una parte, y el confirmado y padre o madre de este por la otra. En el sentir común, este impedimento comprendía también al que, en caso de necesidad, confería el bautismo privado, aceptándose, empero, algunas excepciones ${ }^{60}$.

Puesto que se trataba de una materia definida por el derecho universal, nada dicen sobre el particular ni el sínodo santiaguino de 1895 ni el Concilio Plenario Latinoamericano. Pero participaron de la misma opinión diversos episcopados que sugirieron la eliminación de este impedimento, tanto del originado por el bautismo como por la confirmación ${ }^{61}$. Ya en Concilio Vaticano I (1860-1870) se había suge-

57 Lo hizo prohibiendo "severísimamente" los matrimonios mixtos, esto es, el de parte católico con "otra afiliada a una secta herética o cismática" (can. 1060), y declarando nulo "el matrimonio contraído por una persona no bautizada con otra bautizada en la Iglesia católica o convertida a ella de la herejía o del cisma" (can. 1070 § 1). Los dos, empero, podían celebrarse obteniendo la respectiva dispensa (can. 1061, 1071) la que, de no obtenerse, acarreaba la ilicitud, pero la validez, del matrimonio mixto celebrado; y derechamente la nulidad del segundo.

58 Arturo Alonso Lobo, o.p., Lorenzo Miguelez Domínguez y Sabino Alonso Morán, o.p., Comentarios al Código de Derecho Canónico, Madrid, Biblioteca de Autores Cristianos, 1963, tomo II, 596-597.

59 Donoso, op. cit., II, 150.

60 Ibid., II, 23-24.

61 El arzobispo de Alger y trece episcopados más. Codex..., op. cit., 162. 
rido modificar este impedimento, restringiéndolo al bautizado y padrinos y derogando lo referido al sacramento de la confirmación ${ }^{62}$, por lo que la propuesta de los obispos chilenos era más avanzada en su contenido. Algunos obispos, en cambio, habían sugerido que el parentesco espiritual fuese solo un impedimento impediente $^{63}$; o que simplemente se hiciese una nueva legislación sobre la materia ${ }^{64}$; o que se derogase el proveniente de la confirmación ${ }^{65}$, postulatum que coincidía en parte con quienes sugerían que se produjese solo por el bautismo solemne y entre el bautizado y los padrinos ${ }^{66}$.

El Código de Derecho Canónico no eliminó el impedimento, pero, recogiendo lo que ya se había sugerido en el Concilio Vaticano I, lo limitó al establecer que "solamente el bautizante y el padrino contraen por el bautismo parentesco espiritual con el bautizado" (can. 768, 1079). Se trataba, además, de un impedimento de grado menor, por lo que la dispensa del mismo se concedía con facilidad ${ }^{67}$. Hubo que esperar hasta el Código de Derecho Canónico de 1983 para que la sugerencia de los obispos chilenos fuera finalmente acogida y se eliminase el impedimento de parentesco espiritual.

ii) parentesco legal: la adopción es una institución meramente civil que tiene su origen en el derecho romano, en el que alcanzó un notable desarrollo ${ }^{68}$. La adopción generaba un vínculo estrecho, si bien jurídico, entre el adoptado y los miembros naturales de la familia del adoptante, lo que hizo que los romanos establecieran prohibiciones para los matrimonios entre unos y otros ${ }^{69}$. La Iglesia aceptó en su propio fuero la legislación romana del impedimento de parentesco legal, desde antes del siglo XIII, canonizando dicha legislación, esto es, haciendo canónica la legislación civil. Al tenor de esta canonización, la adopción hecha según las normas de la legislación civil de cada país, si convenía sustancialmente con la adopción romana, producía las mismas prohibiciones que esta; en otras palabras, lo que se precisaba averiguar en cada caso era la conformidad sustancial entre la legislación de cada país y el derecho romano: si dicha conformidad se producía, los impedimentos canónicos no eran los establecidos en la legislación de que se tratase, sino los del derecho romano. De esta manera, la dificultad estribaba en juzgar si la legislación del país acerca de la adopción convenía sustancialmente con la adopción romana. Esta era la disciplina vigente al momento de la codificación.

62 Matthaeus Conte a Coronata O.F.M. cap., Institutiones iuris canonici ad usum utriusque cleri et scholarum. De sacramentis tractatus canonicus, III: De matrimonio et de sacramentalibus, Torino, Marietti, 1957, 558.

63 El obispo de San Alberto en Canadá, el obispo de Londres en Canadá y el obispo de Newark. Codex..., op. cit., 168.

64 El arzobispo de Baltimore y el obispo de Ogdensburgo. Ibid., 169.

65 Los obispos de Cincinnati, los padres de la provincia de Halifax y el obispo de Irenton. Ibid, 169.

66 Los padres de la provincia de Tarragona. Ibid., 170.

67 José de Salazar Abrisquieta, "Capacidad e impedimentos matrimoniales", en Catedráticos de Derecho Canónico de universidades españolas, Derecho canónico, Pamplona, Eunsa, 1977, 428.

68 Alejandro Guzmán Brito, Derecho privado romano, Santiago, Jurídica, 1997, tomo I, 360-363.

69 Ibid., 338-340.

70 Alejandro Guzmán Brito, Andrés Bello codificador. Historia de la fijación y codificación del 
En lo que a Chile se refiere, la adopción estaba regulada en las Siete Partidas, texto del rey Alfonso X el Sabio escrito en el siglo XIII, que había regido esta materia durante todo el período indiano y que había seguido vigente después de la Independencia ${ }^{70}$. En él se había recogido sustancialmente la disciplina del derecho romano y, como explicaba Donoso, existía el impedimento: i) entre el adoptante y el adoptado perpetuamente; ii) entre el adoptado y los hijos naturales (i.e., biológicos) del adoptante mientras dura la adopción, o sea, mientras la persona adoptada no se emancipara; iii) entre el adoptante y la mujer del adoptado, y entre este y la mujer de aquel, siendo este impedimento perpetuo, como el primero ${ }^{71}$.

No fueron solo los obispos chilenos quienes solicitaron la derogación de este impedimento, pues junto a ellos lo hicieron otros 16 episcopados ${ }^{72}$. Sin embargo, no fue esta la única sugerencia referida a este impedimento, porque es posible encontrar otras de variado contenido. Así, algunos, si bien no sugerían la derogación de este impedimento, pedían que al menos se indicasen los casos en que se contraía $^{73}$; otros sugerían examinar primero la posibilidad de posponer los cánones acerca del parentesco legal y quizá derogarlos ${ }^{74}$, coincidiendo en esto con los chilenos, y, si no se podía abrogar, que se determinaran cuidadosamente las condiciones requeridas para que se produjera la adopción ${ }^{75}$. Algunos, en cambio, postulaban que el impedimento se limitase solo al adoptante y $\operatorname{adoptado}^{76}$; o se limitase al máximo ${ }^{77}$, o que fuese un mero impedimento impediente ${ }^{78}$; o que fuese necesario que la adopción se hubiese hecho conforme a las leyes del Estado y el adoptado hubiese pasado a la familia y potestad del adoptante ${ }^{79}$.

El Código de Derecho Canónico no derogó este impedimento dirimente, sino que lo conservó, si bien simplificando notablemente la disciplina: "los que por la ley civil son inhábiles para contraer entre sí matrimonio a causa del parentesco legal que nace de la adopción, por prescripción del derecho canónico no pueden casarse entre sí válidamente" (can. 1.080) ${ }^{80}$. En cambio, “en los países en donde el

derecho civil en Chile, Santiago, Ediciones de la Universidad de Chile, 1982, tomo I, 79-111.

71 Donoso, op. cit., II, 159. Antonio Dougnac Rodríguez, Esquema del derecho de familia indiana, Santiago, Ediciones del Instituto de Historia del Derecho Juan de Solórzano y Pereyra, 2003, 462480 .

72 Los padres de la provincia de Poznan, de la provincia de París, de Holanda, de España, de la provincia de Burgos, el arzobispo de Bamberg, el arzobispo de Guatemala, el patriarca de Lisboa, el obispo de Montalbán, los padres de la provincia de Montreal, de la provincia de Besançon, de la provincia de Halifax, de la provincia de Lyon, el obispo de Tulle, los padres de la provincia de Michoacán y los obispos de Irlanda. Codex..., op. cit., 177.

73 Los padres de la provincia de Albi. Ibid., 170.

74 El arzobispo de Baltimore, el obispo de Ogdensburgo y el obispo de Irenton. Ibid., 169.

75 Los padres de la provincia de Bélgica. Ibid., 172.

76 El obispo de Würzburg y los padres de la provincia de Leopolis. Ibid., 167; y los padres de la provincia de Salzburgo. Ibid., 173.

77 El obispo de Kingston en Canadá y los padres de la provincia de Munich. Ibid., 169.

78 El obispo de San Alberto en Canadá, y el obispo de Londres en Canadá. Ibid., 168.

79 Los padres de la provincia de Tarragona. Ibid., 170.

80 Se trató de un caso de canonización de la ley civil, de manera que el impedimento dirimía el matrimonio por disponerlo así el derecho canónico; y como se trataba de un impedimento de derecho eclesiástico -ni de derecho divino ni natural- era, por lo mismo, dispensable.

81 Donoso, op . cit., II, 163-164. 
parentesco legal que se origina de la adopción, hace por ley civil ilícito el matrimonio, este es también ilícito por derecho canónico" (can. 1.060). El Código Canónico de 1983 conservó también este impedimento, pero, a diferencia del Código de 1917, unificó la disciplina y definió los grados en que dicho impedimento se producía: "no pueden contraer válidamente matrimonio entre sí quienes están unidos por parentesco legal proveniente de la adopción, en línea recta -ascendientes y descendientes adoptivos- y en segundo grado de línea colateral -hermanos adoptivos-" (can. 1.094).

iii) pública honestidad: Donoso definía este impedimento como "una especie de parentesco que nace de los esponsales y del matrimonio rato, es decir, aún no consumado, el cual se contrae entre el varón y los consanguíneos de la mujer; y entre esta y los consanguíneos de aquél"81. Era un impedimento de derecho eclesiástico y, por ello, dispensable. Antes del Concilio de Trento (1545-1563), el impedimento se extendía hasta el cuarto grado $^{82}$, ya naciese de los esponsales o del matrimonio rato, aun cuando uno y otro fueran inválidos, como no lo fuese por defecto de consentimiento o por otra honestidad pública precedente. El Concilio varió esa doctrina en lo que se refería a los esponsales, de manera que el impedimento proveniente de esta causa se extendió solo a la hermana, madre o hija de la mujer y viceversa. En cambio, no varió la disciplina del impedimento cuando su origen era un matrimonio rato. En lo que se refería al impedimento nacido de esponsales, el impedimento permanecía aún después de disueltos aquellos, ya se disolvieren por la muerte, por mutuo consentimiento o por otra causa legal; y, al menos en la opinión más común y probable, nacía el impedimento no solo de los esponsales públicos, celebrados con las solemnidades legales, sino también de los privados y ocultos ${ }^{83}$.

El postulatum del arzobispo Casanova sugería derechamente una madura reflexión sobre la conveniencia de su eliminación, en lo que coincidía con otros nueve episcopados ${ }^{84}$. Hubo, con todo, otras propuestas: así, en lo referido al impedimento nacido ex matrimonio rato, hubo quienes pidieron que se derogase el

82 Contados a la manera canónica y no a la manera romana, o sea hasta el octavo grado colateral romano -primos en tercer grado- o cuarto en línea recta -tatarabuelo, tataranieto-. Desde el siglo IX la Iglesia adoptó la modalidad germánica de contar el parentesco, que solo tenía en cuenta el número de generaciones existente en la línea más larga. De esta manera, el canon 96 del Código de Derecho Canónico de 1917 disponía: “§ 1. La consanguinidad se cuenta por líneas y grados. § 2. En la línea recta hay tantos gados cuantas generaciones, o sea cuantas personas, descontado el tronco. $§ 3$. En la línea colateral, si ambas ramas son iguales, hay tantos grados cuantas generaciones en una de las ramas; si las dos ramas son desiguales, hay tantos grados cuantas generaciones en la rama más larga". La modalidad romana, que es la que recibe el Código Civil y el actual Código de Derecho Canónico de 1983, no varía en cuanto a la línea recta, pero sí en cuanto a la línea colateral en la que "hay tantos grados cuantas personas hay en ambas líneas, descontado el tronco" (can. 108).

83 Concilio Tridentino, Sess. 24, cap. 3 de ref. mat.

84 Además de los padres de la provincia chilena, estaban los obispos de la región subalpina, los padres de la provincia de Burgos, los obispos de la región de Aprutio, los padres de la provincia de Rhemen, los de la provincia de Albi, el arzobispo de Baltimore, el obispo de Irentone, los obispos de Escocia y los padres de la provincia de Bourges. Codex..., op. cit., 175.

85 El patriarca de Luov y el obispo de Kumbakonam. Ibid., 166. 
impedimento que tenía este preciso origen ${ }^{85}$; o que se limitase al primer $\operatorname{grado}^{86} \mathrm{o}$ al segundo grado ${ }^{87}$; o, dicho de otro modo, que en el caso de impedimento nacido ex matrimonio rato se derogasen el tercer y cuarto grado ${ }^{88}$ o se limitase al tercer grado $^{89}$; o que, limitado al primer grado, no fuese un impedimento diferente al de afinidad legítima ${ }^{90}$; o que se restringiese a los grados más próximos ${ }^{91}$.

En lo referido al impedimento nacido ex sponsalibus, no pocos episcopados pidieron derechamente su derogación ${ }^{92}$; otros, que tratándose de matrimonio nulo no consumado, se restringiese el impedimento al primer grado ${ }^{93}$; o derechamente que se derogase el impedimento nacido de matrimonio inválido ${ }^{94}$. Hubo quienes, cualquiera que fuese el origen del impedimento, sugerían restringirlo al primer grado en línea recta ${ }^{95}$. Y, por último, hubo quienes postularon que fuese solo un impedimento impediente ${ }^{96}$.

El Código no aceptó el planteamiento de los obispos chilenos en orden a eliminar este impedimento, pues lo conservó; pero cambió su regulación respecto del derecho anterior, pues, en la nueva configuración, el impedimento se originó solo del matrimonio inválido, consumado o no, y del concubinato público o notorio; y dirimió el matrimonio en primer y segundo grado de línea recta entre el varón y las consanguíneas de la mujer y viceversa (can. 1.078), grados contados a la manera canónica, por lo que se prohibía el matrimonio entre el varón y la madre, abuela, hijas o nietas de la mujer y viceversa. El Código de 1983 igualmente lo conservó, restringiendo aún más el ámbito del mismo, al dirimir el matrimonio en el primer grado de línea recta entre el varón y las consanguíneas de la mujer y viceversa (can. 1.093), grados que ahora se cuentan al modo romano (can. 108), o sea, entre el varón y la madre o hijas de su cónyuge y entre esta y el padre o hijos del marido.

iv) afinidad ilícita: postulaba también el informe del arzobispo Casanova la eliminación del impedimento de afinidad ilícita. La afinidad era definida por Donoso como "el vínculo o proximidad de las personas, proveniente de acto carnal consumado, lícito o ilícito; la contrae el varón con los consanguíneos de la mujer y

86 O sea, con los hermanos, padres o hijos del otro cónyuge. El arzobispo de Argel y otros diez episcopados. Ibid., 163.

87 O sea, hasta los primos hermanos, abuelos o nietos del otro cónyuge. Los padres de la provincia de Antequera y otros doce episcopados. Ibid., 164, 167, 168.

88 O sea, en cuanto al tercer grado, los primos en segundo grado, los bisabuelos y los bisnietos; en cuanto al cuarto grado, los primos en tercer grado, los tatarabuelos y tataranietos. Los padres de la provincia de París. Ibid., 166.

89 O sea, los primos en segundo grado, los bisabuelos y los bisnietos del otro cónyuge. Los padres de la provincia Longobarda y de la provincia de Bombay. Ibid., 165; el arzobispo de Kingston en Canadá y el obispo de Claramont. Ibid., 168.

90 Los padres de la provincia de Ruen y de la provincia de Montreal. Ibid., 167.

91 Los obispos de la provincia de Bélgica. Ibid., 172.

92 Los padres de la provincia de París y otros 25 episcopados. Ibid., 166.

93 O sea, los hermanos, padres o hijos del otro cónyuge. Los padres de la provincia de Luov. Ibid., 167

94 El obispo de Kandy. Ibid., 174.

95 O sea, padres o hijos del otro cónyuge. El obispo de Würzburg. Ibid., 167.

96 El obispo de San Alberto en Canadá y el obispo de Londres en Canadá. Ibid., 168.

97 Donoso, op. cit., II, 164. 
ésta con los consanguíneos de aquél"97. La afinidad ilícita era la que se generaba ex copula fornicaria y, conforme al Concilio de Trento (1545-1563), dirimía el matrimonio en primer y segundo grado ${ }^{98}$. Los grados de afinidad correspondían a los de consanguinidad y se computaban del mismo modo, por lo que, por ejemplo, Pedro, que había conocido carnalmente a Francisca, era afín con la madre e hija de ella, en primer grado de línea recta; con la hermana de la misma, en primer grado de la línea colateral; y con la prima hermana, tía o sobrina, en segundo grado.

A veces, la afinidad ex copula ilicita sobrevenía al matrimonio ya contraído, esto es, cuando el trato carnal tenía lugar con los consanguíneos del consorte en primer o segundo grado. En estos casos el matrimonio no se disolvía, pero privaba al delincuente, como se decía en los textos de la época, del derecho a exigir el débito conyugal, de manera que si lo pedía, pecaba gravemente; en cambio no perdía ese derecho el cónyuge que ignoraba el hecho.

El postulatum de los obispos chilenos de eliminar el impedimento de afinidad ilícita fue compartido por otros 15 episcopados ${ }^{99}$. Hubo quienes postularon abolir el impedimento cuando se hubiese contraído en la infidelidad ${ }^{100}$; o cuando el hecho fuese oculto ${ }^{101}$. Otros simplemente sugirieron restringirlo al primer grado, sin especificar más; o restringirlo al primer grado de la línea recta -el varón con la madre o hijas de la mujer y viceversa- ${ }^{102}$, en tanto que en la otra línea y en los otros grados, derogar el impedimento o simplemente prohibir el matrimonio ${ }^{103}$; o que no dirimiese el matrimonio más allá del primer grado de la línea colateral o derechamente derogarlo ${ }^{104}$; o dejarlo restringido solo a la línea recta ${ }^{105}$.

El Código de Derecho Canónico decidió conservar el impedimento dirimente de afinidad, pero restringido solo a la afinidad lícita; en otras palabras, acogió las peticiones hechas, entre otros por el arzobispo Casanova, en orden a eliminar el impedimento en lo referido a la afinidad ilícita.

\section{Eliminación de algunos grados de consanguinidad y afinidad lícita}

El postulatum del arzobispo Casanova es en esta materia bastante general, pues solo sugiere una madura reflexión en orden a eliminar algunos grados de consanguinidad y afinidad lícita, sin especificar cuáles.

98 Concilio Tridentino, Sess. 24, cap. 4 de ref. matrim.

99 Los obispos de las diócesis de Kandien, los arzobispos de Alger, de Avignon, de Sardi, el patriarca de Luov, los padres de las provincias de Poznan, de Holanda, de Burgos, de Aix, de Agrien, de Montreal, de Sennes, de Albi y los obispos de Escocia y de la región Subalpina. Codex..., op. cit., 163.

100 El obispo de Kumbakonam y los padres de la provincia de Pondicheri. Ibid., 171.

101 Los padres de la provincia de Pondicheri. Ibid., 171.

102 O sea, en primer grado de línea recta con el padre o madre, hijo o hija del otro cónyuge. Los obispos de las diócesis de Anagni, de Montalbán, de Concepción de Chile, los obispos de Hispania y de la región de Umbría, los arzobispos de Bamberg y Guatemala, y los padres de las provincias de Salzburgo, de Halifax, de Quito, de Lyon y de Bourges. Ibid., 165.

103 Los padres de las provincias de París y de Tours y el obispo de Würzburg. Ibid., 166.

104 O sea, no más allá de los hermanos del otro cónyuge. Los padres de las provincias de Rouen,

Brasil, Cincinati, Luov y Michoacán y los obispos de Irlanda. Ibid., 167.

105 Los padres de las provincias de Sydney-Melbourne y de Besançon. Ibid., 172.

106 Donoso, op. cit., II, 158-159. 
Al tiempo de la codificación, la consanguinidad en línea recta-ascendientes y descendientes- irritaba el matrimonio en cualquier grado usque in infinitum; lo hacía por derecho natural, según muchos teólogos, en el primer grado -padre e hija-; según otros lo hacía por derecho natural en todos. Lo cierto es que, según Donoso, nunca se había dispensado en esta línea ${ }^{106}$. En línea colateral, en otro tiempo, la nulidad alcanzaba hasta el séptimo grado canónico, esto es, hasta los primos en sexto grado, limitándose al cuarto grado - primos en tercer grado- en el IV Concilio Lateranense (1215), por lo que para las personas que estaban emparentadas en quinto grado o en quinto con cuarto, tercero o segundo, no había impedimento, disciplina que era la vigente al momento de la codificación. La nulidad era por derecho natural solo en el primer grado, según muchos teólogos, aunque había quienes consideraban que el matrimonio en ese grado, si bien sería gravemente ilícito, no sería nulo si se atendía solo al derecho natural.

La afinidad lícita, por su parte, esto es, la que se originaba por cópula lícita y dirimía el matrimonio entre el varón y las consanguíneas de la mujer o el de esta con los consanguíneos de aquel, se extendía, al tiempo de la codificación, hasta el cuarto grado -primos en tercer grado, en línea colateral, y tatarabuelos y tataranietos en línea recta- del otro cónyuge. Hasta el IV Concilio Lateranense (1215) se prolongaba hasta el séptimo grado, siendo reducido por dicha asamblea conciliar al cuarto grado, disciplina que, en materia de afinidad lícita, conservó el Concilio de Trento (15451563) y era la vigente al momento de la codificación. Disputaban los doctores si la afinidad ex copula conjugali dirimía el matrimonio por derecho natural en el primer grado de línea recta, o sea, entre el padrastro y la entenada, o la suegra y el yerno, existiendo numerosos defensores tanto de la respuesta afirmativa como de la negativa. En la práctica los papas constantemente se habían negado a dispensar en ese grado. En los restantes grados de la línea recta y en los de la línea colateral, se convenía generalmente que el impedimento era de derecho eclesiástico.

El informe del arzobispo de Santiago se limitaba a sugerir, como queda dicho, que se estudiara la posibilidad de eliminar algunos grados como irritantes del matrimonio contraído por quienes estaban ligados por ellos, postulado que coincidió con el de tres episcopados, en cuanto a disminuir los grados del impedimento de afinidad ${ }^{107}$, y con otros tres episcopados en lo referido a disminuir los grados del impedimento de consanguinidad ${ }^{108}$. Otros episcopados fueron más explícitos: en lo que se refiere a la consanguinidad, la mayoría de los episcopados estaban por reducir el impedimento al tercer ${ }^{109}$ y hasta el segundo grado ${ }^{110}$, suprimiendo el

107 Los padres de la provincia longobarda y los arzobispos de Montevideo y de Columbus, en Codex..., op. cit., 165.

108 Los arzobispos de Montevideo, de Columbus y de Québec. Ibid., 165.

109 O sea, primos en segundo grado, bisabuelo y bisnieto del otro cónyuge. Los padres de la provincia de Rothomagen y de Halifax. Ibid., 167, 169.

$110 \mathrm{O}$ sea, hasta primos hermanos en línea colateral y abuelos y nietos en línea recta. El vicario capitular de la diócesis de Marsorum y otros 19 episcopados. Ibid., 164. El arzobispo de Alger y otros seis episcopados. Ibid., 163. Los padres de la provincia de Eger y otros ocho episcopados. Ibid., 168. Los padres de la provincia de Quito. Ibid., 170. Otros siete episcopados. Ibid., 175. El obispo de Abulia. Ibid., 177.

111 Los obispos de las diócesis de Arras y de San Alberto en Canadá. Ibid., 170, 168. 
cuarto grado o dejándolo solo como impedimento impediente ${ }^{111}$. Algunos pedían que se concediese a los obispos facultad para dispensar en algunos grados, sin especificar cuáles ${ }^{112}$, o en tercer grado ${ }^{113}$. Y hubo quien, de conservarse el impedimento hasta el cuarto grado, pedía que se computase conforme a las reglas del derecho civil ${ }^{114}$.

En cuanto a la afinidad lícita, fueron igualmente diversas las sugerencias: el mayor número estuvo por restringirla, no existiendo, empero, unidad de criterio en cuanto a los grados, pues las propuestas iban de restringirlo al tercero ${ }^{115}$, al segundo ${ }^{116}$ e, incluso, al primer grado ${ }^{117}$; o que se diese a los obispos la facultad de dispensar en tercer y cuarto grado ${ }^{118}$, o que simplemente fuese un impedimento impediente.

El Código conservó el impedimento de consanguinidad en los mismos términos en lo que se refería a la línea recta, pero lo redujo al tercer grado -contado a la manera canónica, esto es, primos en segundo grado- en la línea colateral (can. 1.076). Se acogía, así, la sugerencia general del informe Casanova de estudiar la posible reducción de los mismos y, en particular, la de aquellos episcopados que habían solicitado expresamente esa reducción. Por lo demás, el impedimento de consanguinidad en tercer grado de la línea colateral era de grado menor (can. 1.042 $\S 2 \mathrm{n}^{\circ} 1$ ), por lo que se dispensaba fácilmente, aunque adoleciese del vicio de obrepción o subrepción (can. 1.054). En segundo grado de línea colateral, es decir entre primos hermanos, se dispensaba con facilidad y no estaba reservado a la Santa Sede, como sí lo estaba el impedimento de consanguinidad en segundo grado mezclado con primero, esto es, tíos con sobrinos, para cuya dispensa, además, se requerían causas más graves. La dispensa de los demás grados quedaba reservada a la Santa Sede. El Código de 1983 dio un paso más en lo referido a la dispensa del

112 Los obispos de la región de Calabria. Ibid., 170.

$113 \mathrm{O}$ sea, primos en segundo grado en línea colateral, bisabuelos y bisnietos en línea recta. Los padres de las provincias de Poznan, de Salzburgo y de Tarragona, y los obispos de la región Beneventana. Ibid., 176-178.

114 O sea, hasta primos hermanos en línea colateral y abuelos y nietos en línea recta. El obispo de Kandi. Ibid., 174.

$115 \mathrm{O}$ sea, hasta primos en segundo grado en línea colateral, y bisabuelos y bisnietos en línea recta. Los obispos de Jaffa y los padres de la provincia de Cincinati. Ibid., 174; los obispos de la región Beneventana. Ibid., 178; los padres de la provincia de Halifax. Ibid., 169; los padres de la provincia de Bombay, el obispo de Natchez y los obispos de Borussia. Ibid., 175. Otros 15 episcopados. Ibid., 178 .

116 O sea, hasta primos hermanos en línea colateral y abuelos y nietos en línea recta. Lo solicitaban 28 episcopados, entre los que se encontraban los padres de la provincia de Venezuela, el arzobispo de Guatemala y los obispos de las provincias de Bélgica y de Tokio. Ibid., 163; el obispo de San Alberto en Canadá. Ibid., 168; el arzobispo de Kingston en Canadá; el obispo de Claramonte. Ibid., 168; los padres de la provincia de Quito. Ibid., 170; y otros nueve episcopados, entre los cuales los obispos de Brasil, los de la provincia de Michoacán y los obispos de Irlanda. Ibid., 175.

117 O sea, los hermanos del otro cónyuge en línea colateral y padres o hijos en la línea recta. Diez episcopados entre los cuales los padres de la provincia de Burgos, de Montreal y de Escocia. Ibid., 174; los padres de las provincias de Poznan y de Rothoman. Ibid., 176; el obispo de Nueva-Ebora, los padres de la provincia de Cincinati y el obispo de Albano. Ibid., 177.

118 El obispo de Abulia. Ibid., 177.

119 Donoso, op. cit., II, 154. 
impedimento existente entre tíos y sobrinos, al no dejarlo reservado a la Santa Sede (CIC 83, can. $1.078 \S 2)$.

En cuanto a la afinidad, también ella fue conservada en el Código de 1917, si bien la disciplina anterior al Codex fue profundamente reformada, porque, a partir del Código, la afinidad solo tuvo su origen en el matrimonio válido, estuviese o no consumado, y dirimía el matrimonio en cualquier grado de la línea recta y hasta el segundo grado en la línea colateral, esto es, hasta primos hermanos del otro cónyuge (can. $1.077 \S 1$ ). Se acogía, pues, la petición general del informe del arzobispo Casanova, y la más específica de aquellos episcopados que habían solicitado la reducción del impedimento al segundo grado de la línea colateral. El código canónico de 1983 también dio un paso más en esta materia, al eliminar el impedimento de afinidad en la línea colateral, dejándolo solo reducido a la línea recta (CIC 83, can. 1.092).

\section{Racionalismo como impedimento impediente}

Los impedimentos matrimoniales impedientes eran "los que sin invalidarlo, impiden su lícita celebración"119 y, al tiempo de la codificación, se recogían en el verso "Ecclesiae vetitum, tempus, sponsalia, votum" ${ }^{120}$. El primero de ellos -vetitum-comprendía las prohibiciones de celebrar matrimonio establecidas por la Iglesia, entre las que había que entender no solo las prohibiciones emanadas de las leyes generales de la Iglesia ${ }^{121}$, sino también los mandatos especiales de un superior eclesiástico que, con justa causa, hubiese prohibido el matrimonio ${ }^{122}$.

En cuanto al tiempo, se prohibían las nupcias solemnes desde el primer Domingo de Adviento hasta la Epifanía; y desde el Miércoles de Cenizas hasta la octava de Pascua inclusive. Durante estos tiempos, empero, en la América española no se suspendía la celebración de los matrimonios, sino solo la solemne bendición nupcial, llamada comúnmente velación ${ }^{123}$.

Siendo válidos los esponsales, esto es, la "mutua promissio et aceptatio futurarum nuptiarum", aun cuando fueran celebrados sin las formalidades exigidas por las leyes civiles, obligaban en conciencia bajo grave culpa. Pero si, a pesar de su válida celebración, el matrimonio prometido no se celebraba sino que se contraía con otra persona, este segundo matrimonio era válido, si bien ilícito ${ }^{124}$.

\section{Ibid., 171}

121 Como la de contraer matrimonio con excomulgados denunciados, con herejes, o sin que preceda el consentimiento paterno, las amonestaciones, las proclamas o la instrucción de los contrayentes en los rudimentos de la fe.

122 Prohibiciones que podían imponer el obispo, los vicarios y aun el párroco cuando, por ejemplo, se hacía legítima oposición al matrimonio, o había que hacer averiguaciones acerca de algún impedimento.

123 En carta de los obispos chilenos a León XIII, del 13 noviembre 1880, manifestaban su inquietud acerca de dos sentencias romanas que habían rechazado la costumbre de celebrar matrimonios en los tiempos prohibidos, difiriendo la velación para los tiempos en que podía darse la solemne bendición nupcial. Su texto en Retamal Fuentes, op. cit., Vol. II, tomo 1, 354-356.

124 Sobre los esponsales, véase antes lo referido a este tema en la primera de las propuestas episcopales que analizamos en estas páginas.

125 Donoso, op. cit., tomo II, 155. 
En lo referido al voto, no quedaba comprendido en este el voto solemne de castidad, que era uno de los impedimentos dirimentes, sino solo los votos simples de castidad, de entrar en religión, de recibir las órdenes sagradas o de no casarse, todos los cuales obligaban por derecho natural y hacían ilícito el matrimonio celebrado después de haberlos emitido, a menos que mediara dispensa. Si el voto simple de castidad era perpetuo, su dispensa estaba reservada a la Santa Sede, pero los obispos de la América española solían disponer de la facultad de dispensarlo.

La facultad de establecer nuevos impedimentos, dirimentes o impedientes, correspondía solo a la autoridad suprema de la Iglesia, esto es, el concilio general o el Romano Pontífice; y, aunque "en sentir de muchos teólogos" correspondía también esta facultad a los obispos, "es menester confesar que este es un asunto reservado, hoy día, exclusivamente al concilio general y a la Silla Apostólica"125. Es por lo que el informe solicitado por Roma era la ocasión para sugerir el establecimiento de un nuevo impedimento ( $\$ 42)$. El informe del arzobispo Casanova, sin embargo, tenía la novedad de sugerir que el racionalismo fuese considerado un impedimento impediente; es decir, que estuviese prohibido el matrimonio con personas que profesasen dichas ideas, de manera de verse obligadas, antes de celebrar matrimonio, a pedir la respectiva dispensa. No es difícil encontrar el origen de esta sugerencia en las fuertes tensiones que habían caracterizado las relaciones de la Iglesia chilena con las corrientes ideológicas que habían ido desarrollándose en Chile especialmente durante la segunda mitad del siglo XIX.

El informe del arzobispo Casanova fue el único en hacer una sugerencia de esta naturaleza, la que no tuvo mayor suceso, porque el Código nada dijo sobre el racionalismo en particular. Pero la idea que subyacía a esta sugerencia de los obispos chilenos fue recogida en términos más generales por el Código de 1917, cuando dispuso en el canon 1.065 § : “apártese igualmente a los fieles de contraer matrimonio con aquellos que notoriamente abandonaron la fe católica, aunque no estén afiliados a una secta acatólica, o con los que dieron su nombre a asociaciones condenadas por la Iglesia". La hipótesis del informe chileno quedaba de lleno incluida en dicho canon, que, además, tenía la virtud de permitir la inclusión de otras figuras en las que los prelados chilenos quizá no habían pensado.

\section{Informe de Ramón Ángel Jara, obispo de San Carlos de Ancud}

La carta que le enviara el arzobispo Casanova, el 13 de mayo de 1904, no la había recibido el obispo Jara de inmediato, porque se encontraba en Valdivia. Su respuesta está fechada el 14 de junio de $1904^{126}$ y en ella acepta "como propias" las observaciones que le merezcan a los miembros de la comisión designada por el arzobispo Casanova "la revisión de la actual legislación eclesiástica", en atención a "las relevantes prendas de virtud y de ciencia que adornan" a dichos miembros. No obstante, el obispo de Ancud pide que se le permita "llamar la atención [...] hacia los

126 El original en ASV. CIC 17, scat. 96.

127 Donoso, op. cit., II, 17. 
siguientes puntos cuya reforma me atrevería indicar, apoyado en la experiencia del gobierno pastoral". Dichos puntos, diez en total, aparecen incluidos en el mismo texto de la carta respuesta, en párrafos numerados sucesivamente, de los cuales dos se refieren específicamente al matrimonio y un tercero hace una referencia general a los sacramentos que, por su misma generalidad, comprendía también al matrimonio.

\title{
Ritual de sacramentos en lengua vulgar
}

Sugería el obispo Jara disponer de un modo general, sin las limitaciones hasta ese momento establecidas, que todas las preguntas anotadas en el Ritual Romano para la administración de sacramentos que debían ser contestadas por la persona que recibía el sacramento o por sus padrinos, pudiesen hacerse en lengua vulgar, sin hacerlas previamente en lengua latina ( $\$ 5)$. Se trata de una sugerencia más litúrgica que canónica, que comprendía todos los sacramentos y, por ende el matrimonio, cuyo origen hemos de encontrar, de manera particular, en la práctica pastoral del Obispo. En todo caso, conviene tener presente que no se trataba de que todo el rito del sacramento se hiciese en lengua vulgar, sino solo las preguntas que debían ser contestadas por quien recibía el sacramento o sus padrinos.

Al hablar en general de los ritos y ceremonias en la administración de los sacramentos, Donoso hacía presente la dificultad que había para decidir, en cada sacramento, cuándo las omisiones eran graves o leves; pero en seguida afirmaba que, en general, podía decirse que era "más grave infracción la que versa acerca de ciertas circunstancias generalmente recibidas con relación a la materia y forma" y daba como ejemplo, precisamente, el uso "del idioma vulgar"127.

El Concilio Plenario de América Latina había abordado el tema de las lenguas indígenas en la administración de los sacramentos, y lo hacía recordando al $\mathrm{V}$ Concilio Mexicano cuando decía:

\begin{abstract}
"sepan los curas en cuyo territorio hay indios que no hablan castellano, que contribuirán en alto grado a la gloria de Dios, y al cumplimiento de sus propios deberes, si no se contentan con aprender en el idioma indígena las principales preguntas indispensables para la integridad y validez de los sacramentos, y si se esfuerzan por poseer completamente el idioma" 128 .
\end{abstract}

Es por lo que el Plenario exigía a los confesores saber el idioma en que se confesaba el penitente (norma 547); y, hablando de los seminarios menores, el mismo Plenario afirmaba la conveniencia de que los alumnos adquirieran nociones de las lenguas indígenas de cada comarca, "para poder mejor administrarles los sacramentos" (norma 619), la que debían perfeccionar en el seminario mayor, "para que puedan debidamente administrar los sacramentos" (norma 627) ${ }^{129}$. El

128 Concilio Plenario de América Latina, 548.

129 También hablaban de las lenguas indígenas los números 772 y 773, situados en el capítulo dedicado a "las santas misiones a los infieles".

130 Luis García Gutiérrez, "El Manual de Toledo de 1494: Manuale seu baptisterium secundum 
Concilio Plenario, empero, se refería a las lenguas indígenas, en circunstancias que la propuesta del obispo Jara estaba hecha a la lengua vernácula de los fieles en general; de hecho, en su propia diócesis los fieles hablaban en castellano, y es a esa lengua a la que se refería, aunque no la mencionaba expresamente, lo que se explica porque la sugerencia iba dirigida a un texto que tendría vigencia supranacional.

En todo caso, hay que tener en cuenta que en América Latina, por costumbre inmemorial, existía la posibilidad de usar el Manual Toledano (1494) ${ }^{130}$, que introducía la lengua vulgar en determinados momentos de las celebraciones sacramentales, incluido el matrimonio, que es la materia en que dicho manual presenta una mayor originalidad respecto del rito romano, junto con la distribución de la comunión a los enfermos. Se trataba de un texto de rito romano, escrito conjuntamente en latín y en castellano en los textos litúrgicos y catequéticos, en el que pervivían al mismo tiempo huellas de la antigua liturgia de España y de algunos de los usos propios de la diócesis de Toledo. Después de la publicación del Ritual Romano (1614), el Manual adoptó una nueva modalidad, que apareció como apéndice de las ediciones españolas del Ritual de Trento ${ }^{131}$, lo que fue posible gracias a que Paulo V (1605-1621) no impuso el nuevo ritual, sino que concedió la posibilidad de que pervivieran los usos propios de las distintas regiones para la celebración de los sacramentos ${ }^{132}$. Con el paso del tiempo se fue imponiendo el Ritual Romano, pero ello no hizo olvidar del todo el Manual Toledano, del cual se encuentran algunos ejemplares en algunas parroquias del arzobispado de Santiago durante el siglo XIX ${ }^{133}$.

La sugerencia del obispo Jara fue incluida por el consultor Klumper ${ }^{134}$, en el libro en que recogió los postulata episcoporum, en la parte correspondiente al título XVII del libro III del esquema ya aprobado del futuro código, referido a "los ritos sagrados y a los libros litúrgicos", junto con otras once proposiciones, de las que solo la del obispo Jara sugería el uso de la lengua vulgar en algunas partes de la administración del sacramento. Las demás propuestas no tocaron el tema, con excepción de la del arzobispo de Bamberg, que postulaba que se diera amplia potestad al obispo para permitir el uso de la lengua vulgar en funciones sagradas de administración extrasacramental ${ }^{135}$.

El Código nada dijo sobre el particular, y hubo que esperar al Concilio Vaticano II, para que se adoptase en toda la Iglesia una reforma de tal envergadura ${ }^{136}$. Si

usum alme ecclesiae toletane", en Studium Legionense, No 49, León, 2008, 163-180.

131 Por ejemplo, Rituale seu manuale romanum, Pauli V. Pont. Max. Jussu editum, cum cantu Toletano \& Appendice ex Manuali Toletano (Antverpiae, MDCCI).

132 Es lo que permitió que, por ejemplo, el Manual Toledano fuera traducido a la lengua mexicana poco después. Cfr. Francisco Lorra Baquio, Manual mexicano de la administración de los santos sacramentos, conforme al Manual Toledano, compuesto en lengua mexicana, México, Diego Gutiérrez, 1634, 136

133 Sol Serrano e Iván Jaksic, "El poder de las palabras: la Iglesia y el estado liberal ante la difusión de la escritura en el Chile del siglo XIX", en Historia, No 33, Santiago, 2000.

134 Codex..., op . cit., 205-207.

135 Ibid., 205.

136 Concilio Vaticano II, Constitución Sacrosanctum Concilium, art. 36.

137 Concilio Tridentino, Sess. 24, cap. 1, de ref. matrim. 
tomamos en cuenta que la sugerencia se estaba haciendo en 1904, la visión que sobre este punto mostraba el obispo Jara era, al menos, notable.

\section{Dispensa de proclamas matrimoniales}

Una sugerencia específica que, sobre el matrimonio, presentaba Ramón Ángel Jara, era ampliar las causales por las que el obispo podía dispensar las proclamas matrimoniales, con facultad de subdelegar dicha facultad a los curas. Argumentaba que, dadas las dificultades creadas por la ley civil para la celebración del sacramento del matrimonio y en atención a las graves molestias que un viaje reiterado imponía a los fieles cuando estos necesitaban atravesar mares borrascosos y senderos peligrosísimos, eran innumerables los casos en que los fieles faltos de recursos rehusaban aguardar la trina proclamación, contentándose con la inscripción civil y permaneciendo en concubinato $(\S 9)$.

Las moniciones o proclamas que debían preceder al matrimonio fueron prescritas por primera vez en el IV Concilio de Letrán (1215), pero, habiendo caído en desuso, fueron renovadas por el Concilio de Trento (1545-1563), que les dio una nueva forma, a saber: i) debían ser hechas por el párroco ante quien se celebraría el matrimonio, y si los contrayentes eran de parroquias distintas, debían hacerse en ambas parroquias; ii) durante tres días festivos de precepto; iii) debía tratarse de tres días continuos, sin interrumpir las proclamas ya iniciadas; iv) en iglesia o lugar sagrado donde celebrase el párroco con asistencia de fieles; v) durante la misa solemne; vi) públicamente, en alta voz, de manera que todos entendiesen el nombre de los contrayentes y los de sus padres, origen, domicilio y otras circunstancias según la costumbre del lugar ${ }^{137}$. El Concilio de Trento reservaba al obispo la facultad de dispensar las proclamas con justa causa. Estas justas causas no eran enumeradas por el Concilio ni siquiera a manera de ejemplo, por lo que la sugerencia del obispo Jara hemos de entenderla en el sentido de que, entre esas justas causas, se comprendieran las que él proponía.

La propuesta del obispo Jara fue la única presentada en esos términos. Otros episcopados, aunque se refirieron a las proclamas, plantearon derechamente abolirlas y reemplazarlas por dos testigos fidedignos ${ }^{138}$, o disminuir su número ${ }^{139}$, reduciéndolo a una proclamación ${ }^{140} \mathrm{o}$ a dos ${ }^{141}$.

El Código, en materia de proclamas, prácticamente no innovó. Además de conservar su obligatoriedad, dispuso que podían hacerse oralmente en la iglesia, durante la misa o durante otros oficios divinos en que hubiese mayor concurrencia de fieles, en tres domingos consecutivos o días de precepto (can. 1.024); pero que podía hacerse por avisos escritos que debían fijarse en las puertas de la iglesia parroquial o de otra iglesia durante ocho días por lo menos, siempre que en dicho

138 El obispo de Natchete. En Codex..., op. cit., 146.

139 Los padres de la provincia de Halifax y el arzobispo de Cambrai. Ibid., 146.

140 El arzobispo de Bamberg y los padres de la provincia de Munich. Ibid., 144.

141 El obispo de Londres en Canadá y los padres de la provincia de Lyon. Ibid., 145, 146.

142 Coronata, op. cit., Vol. 3, 118. 
plazo coincidieran dos días festivos de precepto (can. 1.025). Se entregaba igualmente al ordinario del lugar la facultad para dispensar de las proclamas, con causa legítima (can. 1.028). De esta manera, con la nueva disciplina, la sugerencia de Ramón Ángel Jara quedaba asumida por el derecho de la Iglesia, pero no se entregó esta materia a los párrocos. En todo caso, como se trataba de una facultad episcopal ordinaria, podía el obispo delegarla en los párrocos, para casos singulares o en general ${ }^{142}$.

\section{Informaciones para el matrimonio de extranjeros}

Pedía el obispo de Ancud facilitar las informaciones para casar a los extranjeros. Las pruebas de soltería, en la forma que eran exigidas, hacían imposible en muchos casos el matrimonio ( $\$ 10)$. Coincidía el obispo Jara en esta materia con el arzobispo Casanova y sus consultores, quienes igualmente habían puesto de relieve en su informe el mismo problema. El tema lo hemos analizado antes, con ocasión del informe del arzobispo de Santiago, por lo que remitimos a las consideraciones hechas en dicha ocasión.

\section{Informe de Plácido Labarca, obispo de Concepción}

El obispo de Concepción respondió, en carta del 5 de septiembre de 1904, incorporando en el texto de la misma los puntos que sometía al criterio y consideración del Arzobispo, "después de implorar las luces del Espíritu Santo y oír las opiniones de sacerdotes competentes en derecho"143. Las tres sugerencias se suceden unas a otras, en párrafos numerados correlativamente, uno de los cuales ( $\$ 2$ ), integrado por cuatro puntos diversos y referido en general a la ampliación de la jurisdicción de los curas en la administración de los sacramentos, se refiere al tema del matrimonio. Las razones, comunes a los cuatro puntos, que justifican la petición, son lo dilatado de las parroquias, la escasez de sacerdotes y lo difícil del recurso al prelado, lo que sucedía generalmente fuera de Europa.

Dispensa de impedimentos matrimoniales de derecho eclesiástico en casos de urgencia

Proponía el obispo que los curas pudiesen dispensar impedimentos matrimoniales de derecho eclesiástico, en casos de verdadera urgencia, en que era difícil y tardío el recurso al prelado. Según explicaba Donoso, era constante en el derecho que el Romano Pontífice, en su carácter de jefe supremo de la Iglesia, pudiese dispensar en todos los impedimentos que dirimían el matrimonio por derecho eclesiástico $^{144}$. Los obispos, en cambio, por derecho común, no podían dispensar de ningún impedimento dirimente, aun cuando los obispos de América Latina podían

\footnotetext{
143 El original en ASV. CIC 17, scat. 96.

144 Donoso, op. cit., II, 186-187.

$1451^{\circ}$ ) en el tercer y cuarto grado así de consanguinidad como de afinidad, y aun en el tercero
} 
dispensar de varios de ellos en virtud de las sólitas ${ }^{145}$; posibilidad que se ampliaba con las facultades que se solían delegar especialmente en ellos ${ }^{146}$. Los párrocos, por su parte, no podían dispensar con sus feligreses "en las leyes y preceptos eclesiásticos, porque esa facultad corresponde a la jurisdicción voluntaria en el fuero externo, de que carecen los párrocos"147.

Las facultades de dispensar impedimentos matrimoniales con que contaban los obispos en general, y los de América en particular, se limitaban solo a algunos impedimentos y solo en situaciones normales, en las que, disponiendo del tiempo necesario, se podían hacer las preces para solicitar la respectiva dispensa. Durante los tres siglos anteriores, sin embargo, los canonistas habían hablado de epiqueya o de licencia presunta para dispensar en ciertos y determinados casos de suma urgencia $^{148}$. Esta doctrina fue recogida por León XIII en un decreto de 20 de febrero de 1888 , por el cual concedió a los obispos facultades amplias para dispensar a los enfermos en gravísimo peligro de muerte, cuando no era posible recurrir a la Santa Sede, de todos los impedimentos, excepto los que procedían del sagrado orden del presbiterado y de la afinidad en línea recta con consumación del matrimonio ${ }^{149}$. De estos decretos fueron concediéndose ampliaciones sucesivas los años $1889^{150}$, $1890^{151}, 1899^{152}$ y $1909^{153}$.

De esta manera, la propuesta del obispo de Concepción significaba una innovación importante, al solicitar que se concediese a los curas unas facultades que solo desde tiempos muy recientes habían empezado a concederse a los obispos. Coincidían con él el los padres de la provincia de Pondycherry, que pedían la misma facultad para todos los sacerdotes ${ }^{154}$. Entre las otras propuestas episcopales, hubo

mixto con segundo, esto es tío y sobrino hijo de un primo hermano; y tratándose de matrimonio ya celebrado, aun en el segundo grado puro esto es primos hermanos, pero solo respecto de los que se convierten al catolicismo de la herejía o de la infidelidad. $2^{\circ}$ ) en el impedimento de pública honestidad proveniente de esponsales válidos. $3^{\circ}$ ) en el impedimento de crimen, neutro tamen conjugum machinante; $4^{\circ}$ ) en el impedimento de parentesco espiritual praeterquam inter levantem et levantum. Las sólitas eran las facultades que la Santa Sede delegaba habitualmente en los obispos americanos en razón de la lejanía con Roma.

146 Dispensar en segundo grado de consanguinidad mixto con primero y en el primero de afinidad en línea colateral, además de que generalmente se concedía en todo impedimento que solía ser dispensado por la Silla Apostólica.

147 Donoso, op. cit., I, 246.

148 Alonso Lobo, o. p., Miguelez Domínguez y Alonso Morán, o. p., op. cit., 496.

149 Litt. Encycl. de la S. Congregación del Santo Oficio, de 20 febrero 1888, en ASS. Vol. 20, 543-544. También en Petrus Gasparri card. (cura), Codicis Iuris Canonici Fontes, Roma, Typis Poliglottis Vaticanis, 1951, Vol. IV, 434-435, n. 1109.

150 Litt. Encycl. de la S. Congregación del Santo Oficio, de 1 marzo 1889, en ASS. Vol. 21, 696. En ibid., tomo IV, 444, n. 1.113.

151 S. Congregación del Santo Oficio, 23 abril 1890, en ASS. Vol. 26, 385-387. En ibid., tomo IV, 448-449, n. 1.121 .

152 S. Congregación del Santo Oficio, 13 diciembre 1899, en ASS. Vol. 32, 500-501. En ibid., tomo IV, 520, n. 1231. Ni este decreto ni los anteriores se mencionan en la edición actualizada de las Instituciones de Donoso hecha en Alemania en 1909.

153 Decreto de la S. Congregación de Sacramentos, de 14 mayo 1909, en AAS. Vol. 1 (1909), 468469. En Gasparri, op. cit., tomo V, 75, n. 2.097.

154 Codex..., op. cit., 154.

155 Los padres de la provincia de Bélgica y de la provincia de Luov. Ibid., 149. 
quienes pedían que las facultades concedidas por el decreto de 20 de febrero de 1888 se extendieran a los impedimentos impedientes ${ }^{155}$; o que derechamente los obispos pudiesen dispensar de impedimentos de derecho eclesiástico en casos ocultos y urgentes ${ }^{156}$; o que pudiesen hacerlo los párrocos, pero con subdelegación del obispo $^{157}$.

El Codex recogió la disciplina innovadora de León XIII y Pío X, pero con notables ampliaciones en sentido más benigno, en los cánones 1.043-1.045. En efecto, de acuerdo con el primero de dichos cánones, en peligro de muerte, para atender a la conciencia y, si el caso lo pedía, a la legitimación de la prole, podían los ordinarios locales dispensar a sus súbditos, dondequiera que residiesen, y a todos los demás que se hallasen dentro de su territorio, no solo de observar la forma prescrita para la celebración del matrimonio, sino también de todos y cada uno de los impedimentos de derecho eclesiástico, tanto públicos como ocultos, y aun múltiples, exceptuados los que procedían del sagrado orden del presbiterado y de la afinidad en línea recta con consumación del matrimonio, evitando el escándalo y, si se concedía dispensa del impedimento de disparidad de cultos o de mixta religión, una vez que se hubiesen dado las garantías de costumbre. En estas mismas circunstancias, establecía el canon 1.044, y solamente en aquellos casos en que ni aun se pudiese acudir al ordinario del lugar, gozaban de igual facultad de dispensar tanto el párroco como el sacerdote que asistía al casamiento, y el confesor, si bien este solo en el acto de la confesión sacramental y para el fuero interno. También los ordinarios locales, según el canon 1.045, ante situaciones de caso perplejo, esto es, cuando el impedimento se descubría estando ya todo preparado para el casamiento y este no podía diferirse sin peligro probable de un mal grave hasta que se obtuviese de la Santa Sede la dispensa, podían conceder dispensa de todos los impedimentos antes referidos, facultad que se extendía también al sacerdote que asistía al matrimonio y al confesor, en el acto de la confesión sacramental y para el fuero interno.

De esta manera, la petición del obispo de Concepción quedaba ampliamente recogida en la nueva codificación.

Facultad para que los párrocos casen feligreses de parroquias limítrofes de distintas repúblicas

Otra de las propuestas del obispo penquista era que consideraba conveniente que los párrocos tuviesen facultad para casar a feligreses de parroquias limítrofes de distintas repúblicas, usando aun de la facultad de dispensar impedimentos si fuere necesario, todo en atención a que las diócesis de América eran muy extensas y a la gran dificultad que había para recurrir a los ordinarios, dificultad que a veces era verdadera imposibilidad.

\footnotetext{
156 Los padres de la provincia de Besançon. Ibid., 150.

157 Los padres de la provincia de Burgos. Ibid., 151.

158 Concilio Tridentino, Sess. 24 cap. 1 de ref. matrim.
} 
Hasta el Concilio de Trento (1545-1563) la Iglesia no dictó normas por las que se estableciera una forma jurídica necesaria para la validez del matrimonio. Fue el famoso capítulo Tametsi del Tridentino el que introdujo una innovación fundamental, al exigir para la validez del matrimonio que este se celebrase ante el párroco propio y dos testigos, o ante otro sacerdote con licencia del mismo párroco o del ordinario. De esta manera el párroco solo podía casar a sus propios parroquianos, pues, para celebrar matrimonio con parroquianos de otra parroquia, lo que en principio le estaba prohibido, necesitaba la respectiva licencia. Es más, el mismo capítulo Tametsi se colocaba en esta posibilidad cuando disponía que:

"si un párroco u otro sacerdote, religioso o secular, se atreviese a unir en matrimonio o a bendecir a esposos de otra parroquia sin licencia de un párroco, aunque presumiera que le era esto lícito por privilegio o costumbre inmemorial, quede suspenso ipso iure hasta que sea absuelto por el ordinario del párroco que debía asistir al matrimonio, o del que había de dar la bendición"158.

Conforme a lo anterior, la sugerencia planteada por el obispo chileno se refería a un problema para el que el derecho vigente tenía solución: la licencia del párroco propio; pero que, en la práctica de los hechos concretos, se veía dificultada por la extensión de las parroquias, que hacía muy difícil o imposible obtener la respectiva licencia. La propuesta del obispo penquista, empero, se refería a parroquianos de parroquias fronterizas, pero de distintas repúblicas; la facultad que se pedía, en consecuencia, no era para casar sin más a feligreses de otras parroquias sin la respectiva licencia, sino de parroquias fronterizas de repúblicas diversas que, en el caso concreto de Concepción, eran de la vecina República de Argentina. En este caso parece clara la dificultad de acudir al ordinario de este país. A decir verdad, no era menester acudir al ordinario, sino que bastaba la licencia del párroco propio, pero esta licencia, con seguridad, no era fácil conseguir, lo que exigía acudir al ordinario.

Casi tres años después de que el obispo de Concepción hiciera su propuesta, el beato Pío IX, mediante el decreto Ne temere, introdujo una modificación fundamental a la legislación tridentina en lo que a la proposición del obispo penquista se refiere, pues dispuso que el matrimonio había de contraerse ante el ordinario o el párroco del lugar y no ante el ordinario o el párroco propio, o un sacerdote delegado por uno de aquellos. Con esta reforma, ya vigente desde antes de la promulgación del Código de Derecho Canónico, vino a quedar superada la dificultad planteada por el obispo Labarca, y se convirtió en derecho común cuando fue recogida en el Codex, que dispuso que "solamente son válidos aquellos matrimonios que se celebran ante el párroco, o ante el ordinario del lugar, o ante un sacerdote delegado por uno u otro, y además ante dos testigos por los menos" (can. 1.094). 
Suprimir los impedimentos dirimentes del matrimonio del cuarto grado puro o con atingencia al tercero, el tercero y cuarto de afinidad lícita y el segundo de la afinidad ilicita

Se trata de una petición que coincidía con otras que sobre la misma materia habían postulado otros episcopados, a las que nos hemos referido precedentemente, con ocasión del informe del arzobispo Casanova.

\section{REFLEXIONES FINALES}

Es posible finalizar estas páginas con las siguientes reflexiones, a modo de conclusión.

1. Por de pronto, todos los obispos chilenos que tenían derecho a ser consultados respondieron en tiempo y forma a la Santa Sede, formulando las sugerencias que se les solicitaban, las que abarcaron diversas materias canónicas, entre las que no estuvo ausente el matrimonio, ya que se trataba de un tema de importancia en la vida sacramental de la Iglesia y de los fieles.

2. La más extensa de las respuestas y, por lo mismo, la que comprende más sugerencias en materia matrimonial, es la del arzobispo de Santiago, Mariano Casanova, que fue expresamente asumida por los obispos de La Serena y de San Carlos de Ancud, y que Casanova denominó la Propuesta de los Obispos Chilenos. Se trató de un informe elaborado por una comisión integrada por personas intelectualmente valiosas, a la cabeza de las cuales estaba el obispo Rafael Fernández Concha, quien, aun cuando no era de los prelados a los que se debía consultar, pudo intervenir indirectamente en su calidad de presidente de dicha comisión.

3. Los informes de los obispos de Ancud y de Concepción son menos extensos, no obstante lo cual el tema del matrimonio no está ausente, expresión de la importancia del mismo en la vida sacramental de la Iglesia chilena de principios del siglo XX. En ellos, más que la reflexión académica, se proyecta la reflexión pastoral, preocupada de los problemas concretos que han de enfrentar los prelados en los aspectos particulares en los que hicieron sus sugerencias.

4. Algunas de las propuestas tuvieron eco en el código final. No queremos con esto decir que las específicas sugerencias de los obispos chilenos hayan sido proyectadas en el Código; solo queremos afirmar que sus sugerencias eran expresión de problemas que debían resolverse, especialmente cuando los postulados de los prelados chilenos eran compartidos por otros episcopados, con los que, en todo caso, parece que no hubo en ningún momento una comunicación sobre la consulta hecha desde Roma. Se trataba de problemas que la Iglesia universal experimentaba en las diversas latitudes donde estaba presente.

5. Otras propuestas no tuvieron la misma fortuna, quedándose como sugerencias que los codificadores no consideraron oportuno recoger. Con todo, ellas tienen el mérito de mostrar las preocupaciones que los prelados criollos tenían acerca de las específicas materias matrimoniales, su sentir sobre las mismas y las pistas por donde veían su solución. 
6. No faltaron propuestas visionarias que, rechazadas en la codificación de 1917, fueron asumidas por la Iglesia con el correr del tiempo, aparecieron en el Concilio Vaticano II y se hicieron ley eclesial recién en el código canónico juanpaulino de 1983. En este sentido son notables algunas intuiciones del entonces obispo de San Carlos de Ancud, don Ramón Ángel Jara. 